\title{
Multimodal Imaging for DREADD-Expressing Neurons in Living Brain and Their Application to Implantation of iPSC-Derived Neural Progenitors
}

\author{
(-Bin Ji, ${ }^{1,7}$ Hiroyuki Kaneko, ${ }^{1}$ Takafumi Minamimoto, ${ }^{1}$ @Haruhisa Inoue, ${ }^{5,7}$ Hiroki Takeuchi, ${ }^{5}$ Katsushi Kumata, ${ }^{2}$ \\ Ming-Rong Zhang, ${ }^{2}$-Ichio Aoki, ${ }^{3}$ @Chie Seki, ${ }^{1}$ Maiko Ono, ${ }^{1}$ Masaki Tokunaga, ${ }^{1}$ Satoshi Tsukamoto, ${ }^{4}$ Koji Tanabe, ${ }^{5}$ \\ Ryong-Moon Shin, ${ }^{1}$ Takeharu Minamihisamatsu, ${ }^{1}$ Seiji Kito, ${ }^{4}{ }^{\circ}$ Barry J. Richmond, ${ }^{6}$ Tetsuya Suhara, ${ }^{1,7}$ \\ and $\odot$ Makoto Higuchi ${ }^{1,7}$ \\ ${ }^{1}$ Department of Functional Brain Imaging Research, ${ }^{2}$ Department of Radiopharmaceuticals Development, ${ }^{3}$ Department of Molecular Imaging and \\ Theranostics, and ${ }^{4}$ Laboratory of Animal and Genome Science Section, National Institute of Radiological Sciences, National Institutes for Quantum and \\ Radiological Science and Technology, Chiba 263-8555, Japan, ${ }^{5}$ Center for iPS Cell Research and Application (CiRA), Kyoto University, Kyoto, Kyoto \\ 606-8507, Japan, 'Laboratory of Neuropsychology, National Institute of Mental Health, National Institutes of Health, Department of Health and Human \\ Services, Bethesda, Maryland 20892, and ${ }^{7}$ Core Research for Evolutional Science and Technology (CREST), Japan Science and Technology Agency (JST), \\ Kawaguchi, Saitama 332-0012, Japan
}

Chemogenetic manipulation of neuronal activities has been enabled by a designer receptor (designer receptor exclusively activated by designer drugs, DREADD) that is activated exclusively by clozapine- $\mathrm{N}$-oxide (CNO). Here, we applied $\mathrm{CNO}$ as a functional reporter probe to positron emission tomography (PET) of DREADD in living brains. Mutant human M4 DREADD (hM4Di) expressed in transgenic (Tg) mouse neurons was visualized by PET with microdose $\left[{ }^{11} \mathrm{C}\right] \mathrm{CNO}$. Deactivation of DREADD-expressing neurons in these mice by nonradioactive $\mathrm{CNO}$ at a pharmacological dose could also be captured by arterial spin labeling MRI (ASL-MRI). Neural progenitors derived from hM4Di Tg-induced pluripotent stem cells were then implanted into WT mouse brains and neuronal differentiation of the grafts could be imaged by $\left[{ }^{11} \mathrm{C}\right] \mathrm{CNO}$-PET. Finally, ASL-MRI captured chemogenetic functional manipulation of the graft neurons. Our data provide the first demonstration of multimodal molecular/functional imaging of cells expressing a functional gene reporter in the brain, which would be translatable to humans for therapeutic gene transfers and cell replacements.

Key words: cell replacement therapy; clozapine- $\mathrm{N}$-oxide (CNO); designer receptor exclusively activated by designer drugs (DREADD); induced pluripotent stem cell (iPSC); positron emission tomography (PET)

\section{Significance Statement}

The present work provides the first successful demonstration of in vivo positron emission tomographic (PET) visualization of a chemogenetic designer receptor (designer receptor exclusively activated by designer drugs, DREADD) expressed in living brains. This technology has been applied to longitudinal PET reporter imaging of neuronal grafts differentiated from induced pluripotent stem cells. Differentiated from currently used reporter genes for neuroimaging, DREADD has also been available for functional manipulation of target cells, which could be visualized by functional magnetic resonance imaging (fMRI) in a real-time manner. Multimodal imaging with PET/fMRI enables the visualization of the differentiation of iPSC-derived neural progenitors into mature neurons and DREADD-mediated functional manipulation along the time course of the graft and is accordingly capable of fortifying the utility of stem cells in cell replacement therapies.

\section{Introduction}

Reporter gene systems have offered techniques to assess mechanisms regulating the expression of a gene of interest in organisms

Received April 18, 2016; revised Aug. 19, 2016; accepted Sept. 7, 2016.

Author contributions: B.J., T. Minamimoto, h.i., M.-R.Z., R.-M.S., B.J.R., T.S., and M.H. designed research; B.J., H.K., H.T., K.K., I.A., C.S., M.O., M.T., S.T., K.T., T. Minamihisamatsu, and S.K. performed research; B.J., I.A., and C.S. analyzed data; B.J. and M.H. wrote the paper. and to label and track a specific cellular population (Schenborn and Groskreutz, 1999; Kvon, 2015). Visualization of a reporter gene product in the brain would be ideally enabled by a nonin- 
vasive imaging modality without damaging cranial and extracranial tissues for translational research and development. In addition, reporter-aided in vivo monitoring of the nervous system would be applied to, not only simple labeling of a target cell group, but also to assessments of functional statuses of reporterexpressing cells toward therapeutic use of a reporter probe (Thakur et al., 2015). The technology is not limited to imaging of endogenous cells expressing a reporter transgenically or via gene transfer methods, but could also be used for exogenous cell components transplanted into the brain for therapeutic purposes (Duffy et al., 2014).

Indeed, cell replacement with embryonic stem cells (ESCs) or induced pluripotent stem cells (iPSCs) is a promising therapeutic strategy for the treatment of neurodegenerative disorders. Therapeutic ESCs and iPSCs could be differentiated into a neural lineage after being implanted into brains bearing pathologies, leading to symptomatic improvement in experimental animal models of Parkinson's disease (Sanchez-Pernaute et al., 2008; Wernig et al., 2008; Hargus et al., 2010; Doi et al., 2012) and spinal cord injury (Kumagai et al., 2009; Abematsu et al., 2010; Fujimoto et al., 2012).

Further development of these therapeutic approaches, however, is hampered by the lack of practical technologies for monitoring the survival, differentiation, and functionality of cellular grafts and for manipulating activities of these implants. Live grafts differentiated into a target lineage could be captured by detecting expression of reporters in these therapeutic components driven by a cell-type-specific promoter. Fluorescence and luminescence optical imaging has shown partial success in demonstrating graft survival in rodents (Okada et al., 2005; Abematsu et al., 2010), but this technique may not be applicable to deepbrain visualization in animal models and humans due to limited penetration of optical signals through tissues. Alternatively, expression of ferritin reporter resulted in enhanced paramagnetic iron uptake into the grafts, enhancing MRI signals (Vande Velde et al., 2012). Despite the potential utility, there have been difficulties in sensitively and quantitatively assaying signals derived from iron-enriched implants in the brain using current MRI techniques.

Positron emission tomography (PET) enables high-sensitivity mapping of target molecules using a specific radioligand and offers an imaging-based quantitative biomarker sharable by animal models and human subjects in translational research and development. In the field of oncology and oncoimmunology research, PET imaging of a reporter gene product was applied to the visualization of grafted cells with the aid of specific ligands, as exemplified by the use of herpes simplex virus type 1 thymidine kinase and its radioactive substrate for monitoring the localization and retention of cancer cells or tumor-specific T lymphocytes transplanted into animals (for review, see Herschman, 2003). A gene reporter for brain PET imaging should react exclusively with a blood-brain barrier (BBB)-permeable exogenous radiolabeled ligand and may also offer noninvasive functional manipulation of these grafts if it can be stimulated by interacting with a specific ligand at pharmacological concentration. This property would help to verify synaptic connectivity of the grafts to host neurons in living brains and to control neuronal activity in selected brain

The authors declare no competing financial interests.

Correspondence should be addressed to Makoto Higuchi, M.D., Ph.D., Molecular Imaging Center, National Institute of Radiological Sciences, 4-9-1, Anagawa, Inage-ku, Chiba 263-8555, Japan. E-mail: mhiguchi@nirs.go.jp.

DOI:10.1523/JNEUROSCI.1279-16.2016

Copyright $\odot 2016$ the authors $\quad 0270-6474 / 16 / 3611545-15 \$ 15.00 / 0$ regions for functional repair of disordered brains. There has been no reporter gene possessing the above two properties concurrently until recently. A potential chemogenetic approach has been provided by the development of genetically engineered G-protein-coupled receptors (GPCRs) termed DREADDs (designer receptors exclusively activated by designer drugs), which can be activated by otherwise inert drug-like small molecules. The mutations in two conserved orthosteric-site residues of human M3 or M4 muscarinic acetylcholine receptor (mAChR) cause a loss in responsiveness to acetylcholine but a gain in reactivity with a synthetic ligand, clozapine- $\mathrm{N}$-oxide (CNO) (Armbruster et al., 2007; Alexander et al., 2009). CNO can stimulate $\mathrm{G}_{\mathrm{i}}$-coupled human M4 mAChRDREADD (hM4Di) exclusively, resulting in membrane hyperpolarization and neuronal silencing without affecting DREADD-negative cells.

In the present study, we have developed multimodal assaying systems that were applied to PET imaging of hM4Di expressed in neurons differentiated from iPSCs implants and to arterial spin labeling MRI (ASL-MRI) of the chemogenetic suppression of graft activities.

\section{Materials and Methods}

Animal models. The M4 mAChR sequence was cloned from human tissue and PCR with mutagenic primers was performed to introduce mutations of two conserved orthosteric site residues $\left(\mathrm{Y}^{113} \mathrm{C}, \mathrm{A}^{203} \mathrm{G}\right)$ on this gene. The resultant hM4Di sequence was cloned into the XhoI site of plasmid pH7024, which was generated by inserting neuron-specific human Thy-1 promoter element and Simian virus 40 poly-A sequence (pA) into cloning vector pTZ18u (Qian et al., 1998). The plasmid was then digested at the EcoRI and SalI sites to obtain Thy1-hM4Di-pA and pronuclear injection of C57BL/6J mouse oocytes was conducted using this digestion product.

Two transgenic $(\mathrm{Tg})$ mouse lines were established from chimeric founders carrying the transgene and a high-expressor line expressing 29 copies of the transgene was used in the subsequent experiments. Mice were maintained on a C57BL/6J background and the transgene was detected by PCR with forward (GAGAGGGGGAATGGAGAGAG) and reverse (TCATAGCGATTGTGGGATGA) primer probes. The mice were kept and handled in accordance with the National Institutes of Health's Guide for the Care and Use of Laboratory Animals and our institutional guidelines. Protocols for the present animal experiments were approved by the Animal Ethics Committees of the National Institute of Radiological Sciences and the Central Institute for Experimental Animals (CIEA). Mice heterozygous for the transgene and their non-Tg WT littermates were used for further studies.

Reagents and antibodies. The following reagents were of analytical grade and were commercially purchased: CLZ and CNO were from Enzo Life Sciences and $N$-desmethylclozapine (norclozapine) was from Tocris Bioscience. All other chemicals were also of analytical grade and were commercially available.

The following commercial antibodies were used in this study: rabbit polyclonal antibodies against ionized calcium binding adapter molecule-1 (Iba-1; Wako Pure Chemicals), M4 mAChR (H-175; Santa Cruz Biotechnology), MAP2 (Abcam) and DsRed (Living Colors; Clontech Laboratories), rat monoclonal antibody against GFAP (clone 2.2B10; Zymed/Invitrogen), and mouse monoclonal antibody against NeuN (clone A60; Millipore). In addition, we raised a new rabbit polyclonal antibody against a peptide sequence (TSSSHNRYE) corresponding to the 20 to 28 positions in human M4 mAChR because commercial antibody $\mathrm{H}-175$ did not yield specific signals in immunoblot analyses.

Preparation of iPSCs for intracranial implantation and in vitro assays. Embryonic fibroblasts were isolated from embryos of hM4Di Tg mice at embryonic day 13.5 (E13.5). Reprogramming of these cells to iPSCs (i.e., hM4Di-iPSCs) was performed by retrovial transduction of Gli-like transcription factor Glis1 together with three transcription factors dubbed OSK (Oct3/4, Sox2, and Klf4; Maekawa et al., 2011). Similarly, tail tip fibroblasts were isolated from adult Tg mice displaying expression of 
DsRed under the control of chicken $\beta$-actin promoter coupled with cytomegalovirus immediate early enhancer (Vintersten et al., 2004) and iPSCs constitutively expressing a fluorescent protein DsRed (i.e., DsRediPSCs) were reprogrammed from these fibroblasts by retrovirally transfecting Klf4, Oct3/4 and Sox2 (Nakagawa et al., 2008). hM4Di-iPSCs and DsRed-iPSCs were maintained on a sheet of SNL feeder cells and were passaged using a standard method.

iPSC preparation for implantation and in vitro neuronal differentiation and electrophysiological analysis. Briefly, undifferentiated iPSCs were disassociated and seeded on a 96-well round bottom plate and cultured for 1 week in mEB medium consisting of DMEM/Ham's F12 Glutamax containing 5\% KSR knock-out serum replacement (10565-018; Invitrogen Life Science Technologies), 1\% nonessential amino acid solution (11140050; Invitrogen Life Science Technologies), 1\% penicillin-streptomycin solution (168-23191; Wako Pure Chemicals), 0.2\% 2-mercaptoethanol (21985-023; Invitrogen Life Science Technologies), 1\% N2 supplement (17502-048; Invitrogen Life Science Technologies) containing $2 \mu \mathrm{M}$ dorsomorphin (P5499; Sigma-Aldrich), and $10 \mu \mathrm{M}$ SB431542 (S4317; Sigma-Aldrich) for the formation of embryonic bodies (EBs) enriched with neural progenitors.

iPSC-derived EBs were dissociated with Accumax (ICT AM105; Innovative Cell Technologies), followed by filtration with CellStrainer (pore size $70 \mu \mathrm{m}$, Falcon; BD Biosciences) to obtain a single-cell suspension. The cells for implantation were used without further treatment and those for in vitro neuronal differentiation and electrophysiological analysis were collected with polysialic acid-neural cell adhesion molecule (PSANCAM)-positive sorting for an enrichment of neuronal cells according to a published study (Hargus et al., 2010). Briefly, the single-cell suspension $\left(0.1 \mathrm{ml} ; 1.4 \times 10^{8} / \mathrm{ml}\right)$ was incubated with $10 \mu \mathrm{l}$ of FcR Blocking Reagents (130-092-575; Miltenyi Biotec) for $10 \mathrm{~min}$ at $4^{\circ} \mathrm{C}$, followed by additional incubation with $20 \mu \mathrm{l}$ of PSA-NCAM MicroBeads (130-092966; Miltenyi Biotec) for $15 \mathrm{~min}$. Two milliliters of culture medium was added to the cell mixture, followed by centrifugation at $300 \times g$ for $5 \mathrm{~min}$. The supernatant was removed and this procedure was repeated twice. The pellet was resuspended in $500 \mu \mathrm{l}$ of medium and then loaded onto LS Columns (130-042-401; Miltenyi Biotec), which were placed in the magnetic field of a QuadroMACS Separator (130-090-976; Miltenyi Biotec). The columns were rinsed 3 times with $3 \mathrm{ml}$ of autoMACS Running Buffer (130-091-221; Miltenyi Biotec). Magnetically isolated PSA-NCAMpositive cells were retained in the columns and eluted as a positively selected cell fraction after removing the columns from the magnet. Isolated PSA-NCAM-positive cells $\left(1 \times 10^{4} / 10 \mu \mathrm{l}\right)$ were seeded on polyornithine/laminin-coated coverglass and on MED64 Probe Multielectrode Dish (MED-P515A; Alpha MED Scientific) containing 64 electrodes in an $8 \times 8$ grid with interelectrode spacing of $150 \mu \mathrm{m}$ for immunohistochemical and electrophysiological analyses, respectively. Multielectrode recording was performed using the MED64 system (Alpha MED Scientific) at $14 \mathrm{~d}$ after cell seeding. The recordings were performed three times as follows. The first recording was performed as baseline and the second was done $30 \mathrm{~min}$ after careful addition of $\mathrm{CNO}$ ( 1 $\mu \mathrm{M})$ into the culture medium. The medium was then replaced with fresh medium without $\mathrm{CNO}$ and incubated for $60 \mathrm{~min}$ for washout of CNO. The same handling was repeated twice more and the third recording was performed $30 \mathrm{~min}$ after the last washout for determination of the recovery of neuronal activity. The spikes were counted with a voltage threshold of $25 \mu \mathrm{V}$ and the frequency was determined for each $5 \mathrm{~min}$ of recording by active electrodes.

Implantation of PSC-derived neural progenitors into adult mouse brain. Implantations of neural progenitor cells prepared from hM4Di-iPSCs and DsRed-iPSCs into the brains of WT mice were conducted as described previously (Ji et al., 2008). Briefly, male WT C57BL/6J mice (12-24 weeks old) were anesthetized with $1.5 \%(\mathrm{v} / \mathrm{v})$ isoflurane and placed in a stereotactic frame (Narishige). Using a $10 \mu$ l Hamilton syringe, $2 \mu \mathrm{l}$ of cell suspension $(20,000 \mathrm{cells} / \mu \mathrm{l})$ was injected over $4 \mathrm{~min}$ into the right hippocampus (stereotactic coordinates: anteroposterior, $2.8 \mathrm{~mm}$; mediolateral, $2.0 \mathrm{~mm}$; dorsoventral $2.0 \mathrm{~mm}$ ) unless otherwise indicated. The needle was left in place for $3 \mathrm{~min}$ before being withdrawn. These mice were scanned with a microPET system at $20 \pm 1,40 \pm 1$, and $60 \pm 1 \mathrm{~d}$ after implantation unless otherwise indicated.
Locomotive activity test. A locomotive activity test was performed from 1:00 P.M. to 5:00 P.M. (light cycle). M4D Tg and WT mice were injected intraperitoneally with $1 \mathrm{mg} / \mathrm{kg} \mathrm{CNO}$ or vehicle and allowed to move freely in a home cage equipped with a computer-operated animal activity monitoring system (Ohara Ika Sangyo). Data collection over $2 \mathrm{~h}$ was initiated at $30 \mathrm{~min}$ after the $\mathrm{CNO}$ administration. The total distance moved was measured as an index of locomotive activity.

Immunohistochemical and histochemical analyses. After the last PET scan, mice were deeply anesthetized with sodium pentobarbital and then transcardially perfused with PBS. Brain tissues were removed and fixed with $4 \%$ paraformaldehyde in phosphate buffer $(\mathrm{PB})$ overnight, followed by cryoprotection with $30 \%$ sucrose in PB. Ten-micrometer-thick frozen sections were generated in a cryostat (HM560; Carl Zeiss) and immunostained using fluorophore-conjugated secondary antibodies (Invitrogen) as described previously (Maeda et al., 2007). Similarly, immunofluorescence staining of cultured cells on a cover glass was carried out. All stained samples were examined by a Research Inverted Microscope (IX83; Olympus) or an all-in-one fluorescence microscope (BZ-9000; Keyence), which was capable of tiling photomicrographs and merging them into a high-resolution image with a large field of view (FOV).

Western blotting. For biochemical analyses, the cultured undifferentiated iPSCs, EBs, and differentiated iPSC-derived neuronal cells were collected with cell scrapers and lysed in RIPA buffer. The cell samples containing $2.5 \mu \mathrm{g}$ of proteins were applied to a $10 \%$ SDS polyacrylamide gel. After electrophoresis and transfer of proteins to a polyvinylidene fluoride membrane (Immobilon P; Millipore), the membrane was immersed in Tris-buffered saline ( $150 \mathrm{~mm} \mathrm{NaCl}, 10 \mathrm{~mm}$ Tris-HCl, $\mathrm{pH} 8.0$ ) containing $0.05 \%(\mathrm{v} / \mathrm{v})$ Tween 20 and $3 \%(\mathrm{w} / \mathrm{v})$ bovine serum albumin (BSA) and then reacted with commercial antibody H-175 (1:1000) or a newly developed original antibody (1:1000) against nonmutated human M4 mAChR in TBS containing 0.05\% (v/v) Tween 20 and $0.1 \%(\mathrm{w} / \mathrm{v})$ BSA overnight. The primary antibodies were detected by HRP-conjugated anti-IgG antibodies (GE Healthcare) and an enhanced chemiluminescence method (GE Healthcare).

Radiosynthesis and small animal PET imaging. $\left[{ }^{11} \mathrm{C}\right] \mathrm{CNO}$ and $\left[{ }^{11} \mathrm{C}\right] \mathrm{CLZ}$ were radiosynthesized by reacting $\mathrm{N}$-desmethylclozapine with $\left[{ }^{11} \mathrm{C}\right] \mathrm{CH} 3 \mathrm{I}$ as described previously (Bender et al., 1994). Their radiochemical purity and specific radioactivity exceeded $97 \%$ and $37 \mathrm{GBq} /$ $\mu \mathrm{mol}$, respectively, at the end of synthesis. PET scans were performed using a microPET Focus 220 animal scanner (Siemens Medical Solutions) as described previously (Maeda et al., 2007). The mice were anesthetized with $1.5 \%(\mathrm{v} / \mathrm{v})$ isoflurane and a $30 \mathrm{Ga}$ needle connected to a 1 $\mathrm{ml}$ polypropylene syringe via a length of polyethylene tubing was inserted into the tail vein. Emission scans were acquired for $60 \mathrm{~min}$ in 3D list mode with an energy window of $350-750 \mathrm{keV}$ immediately after $\left[{ }^{11} \mathrm{C}\right] \mathrm{CNO}(24 \sim 36 \mathrm{MBq})$ or $\left[{ }^{11} \mathrm{C}\right] \mathrm{CLZ}(8 \sim 10 \mathrm{MBq})$ was injected intravenously. Similarly, dynamic PET scans with $\left[{ }^{11} \mathrm{C}\right] \mathrm{CNO}$ and $\left[{ }^{11} \mathrm{C}\right] \mathrm{CLZ}$ were initiated $5 \mathrm{~min}$ after intravenous administration of $1 \mathrm{mg} / \mathrm{kg}$ unlabeled CNO or CLZ. Images were reconstructed by either maximum a posteriori method or filtered back projection using a $0.5 \mathrm{~mm}$ Hanning filter. Volumes of interest (VOIs) were placed on the neocortex, hippocampus, and cerebellum of hM4Di Tg and WT mice in a blinded manner or on iPSC-implanted sites and contralateral counterparts of WT mice using image analysis software (PMOD Technologies) with reference to an MRI template generated as described previously (Maeda et al., 2007). The location of implantation sites was confirmed by immunohistochemistry of postmortem tissue sections. Tracer uptake in each VOI was estimated as the percentage of injected dose per tissue volume. All individuals showing tumorigenesis in the postmortem analysis were excluded from the following statistical analysis.

ASL perfusion MRI. Cerebral blood flow (CBF) was quantified using the FAIR (flow-sensitive alternating inversion-recovery) ASL method (Kim, 1995) with echoplanar imaging readout $(3$ slices, slice thickness $=$ $1 \mathrm{~mm}$, axial FOV $=25.6 \times 25.6 \mathrm{~mm}$, matrix $128 \times 128$, number of repetitions $=2, \mathrm{TR}=12000 \mathrm{~ms}, \mathrm{TE}=46.8 \mathrm{~ms}$, scan time $=4 \mathrm{~min} 13 \mathrm{~s}$ ) in 7T-. Two quantitative $\mathrm{T}_{1}$ datasets were acquired and the first and second $\mathrm{T}_{1}$ series used selective and nonselective inversions, respectively. The apparent $T_{1}$ was calculated for the first $\left(T_{1 \text { selective }}\right)$ and second $\left(\mathrm{T}_{1 \text { nonselective }}\right)$ datasets and then the CBF was estimated using the 

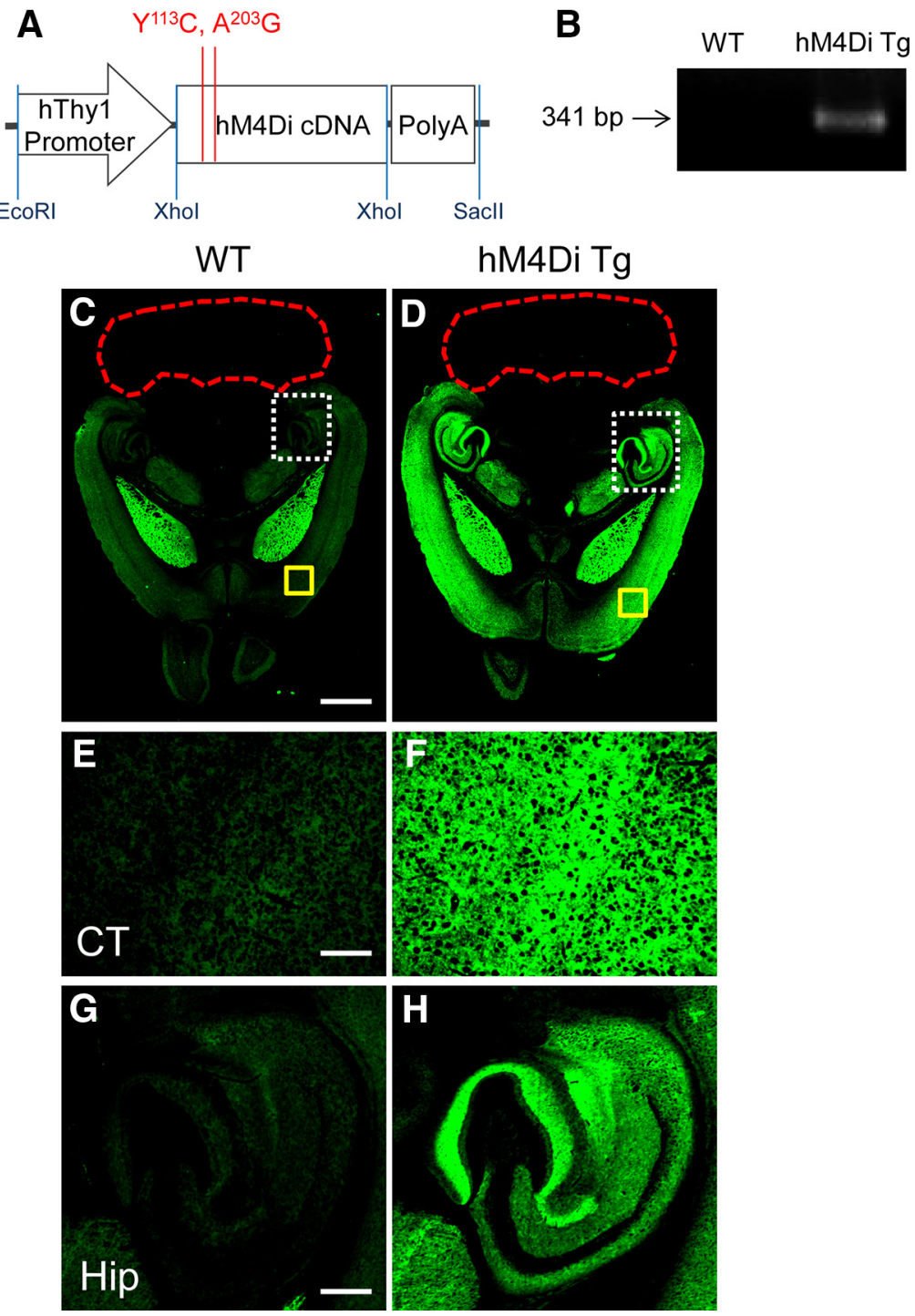

Figure 1. Expression of hM4Di in the Tg mouse. $\boldsymbol{A}$, Expression construct with mutations of two conserved orthosteric site residues $\left(\mathrm{Y}^{113} \mathrm{C} / \mathrm{A}^{203} \mathrm{G}\right)$ in human M4 mAChR (Chrm4 ) used to generate hM4Di Tg mouse. $\boldsymbol{B}, \mathrm{PCR}$ product of the hM4Di transgene with expected molecular size at 341 bp in WT and Tg mice. The image is representative of $>10$ assays. $\mathbf{C}-\boldsymbol{H}, \mathbf{C}$ and $\boldsymbol{D}$ show low-power immunohistochemical images of $\mathrm{H}-175$, a commercial antibody against human $\mathrm{M} 4 \mathrm{mAChR}$, in horizontal brain sections containing the neocortex (CT; areas outlined with yellow solid lines in $\boldsymbol{C}$ and $\boldsymbol{D}$ are shown in $\boldsymbol{E}$ and $\boldsymbol{F}$ at high power, respectively), hippocampus (Hip; areas outlined with white dotted lines in $\boldsymbol{C}$ and $\boldsymbol{D}$ are shown in $\boldsymbol{G}$ and $\boldsymbol{H}$ at high power, respectively), and cerebellum (outlined with red dotted lines) in WT $(\boldsymbol{C}, \boldsymbol{E}, \boldsymbol{G})$ and hM4Di Tg $(\boldsymbol{D}, \boldsymbol{F}, \boldsymbol{H})$ mice. The images are representative of data from 5 WT and $4 \mathrm{Tg}$ mice. Scale bars: $\mathbf{C}, \mathbf{D}: 1 \mathrm{~mm} ; \boldsymbol{E}-\boldsymbol{H}, 200 \mu \mathrm{m}$.

following equation: $\mathrm{CBF}=\lambda\left(1 / \mathrm{T}_{1 \text { selective }}-1 / \mathrm{T}_{1 \text { nonselective }}\right)$, in which the blood-brain partition coefficient $\lambda$ was set at $90 \mathrm{ml} / 100 \mathrm{~g}$ (Kim, 1995). Quantitative analyses for Tg versus WT mice were performed in a blinded manner.

Statistical analysis. Statistical analyses in the present study were performed with SPSS software. For comparisons between groups, one-way or two-way ANOVA or Student's $t$ tests were performed, as indicated in the Results. Difference between groups was considered significant when the two-sided $p$-value was $<0.05$.

\section{Results}

\section{Expression of DREADD in hM4Di Tg mice}

We first generated Tg mouse lines expressing hM4Di under the control of neuron-specific Thy-1 promoter to examine the utility of the DREADD-CNO system for in vivo PET imaging and functional manipulation of a particular neuronal subset. Brain tissues obtained from heterozygous hM4Di Tg mice in a line with the highest level of transgene expression were analyzed immunohistochemically (Fig. 1). Immunoreactivity of $\mathrm{H}-175$, an antibody raised against nonmutant human M4 mAChR, was consistent with the known biodistribution of endogenous mouse $\mathrm{M} 4 \mathrm{mAChR}$ in wildtype (WT) mouse brains, implying crossreaction of this antibody with murine homologs (Fig. 1C, E, G). H-175 immunolabeling was markedly intensified in the forebrain of hM4Di Tg mice and the high-level expression of DREADD in the frontal and parietal cortices, hippocampus, and thalamic nuclei (Fig. 1D,F,H) was in sharp contrast with weak immunostaining, likely due to endogenous mouse M4 mAChR in these areas of WT mice. H-175 immunoreactivity was negligible in the cerebellum of WT and Tg mice (Fig. 1C,D). Tg DREADD in neurons was localized predominantly in axons and synapses, which was similar to known subcellular compartmentalization of endogenous mAChRs.

\section{PET visualization of DREADD \\ expression in living $\mathrm{Tg}$ mouse brains} The affinity of clozapine (CLZ) and its two major metabolites, $\mathrm{CNO}$ and $\mathrm{N}$-desmethyl CLZ (NDMC), for hM4Di was reported to be $25-50$ times higher than that for nonmutant human M4 mAChR (Nawaratne et al., 2008). Of these ligands, $\mathrm{CNO}$ showed the highest selectivity for hM4Di versus nonmutant M4 mAChR ( $\sim 50$-fold difference). The dissociation constant of $\mathrm{CNO}$ for nonmutant M4 mAChR $(\sim 12,500 \mathrm{nM})$ was also 10-50 times higher than those of CLZ and NDMC (Nawaratne et al., 2008) and it is therefore unlikely that binding of $\mathrm{CNO}$ to endogenous M4 mAChR produces significant background signals in PET detection of DREADD in the brain. In addition, no possible radiolabeling sites for ${ }^{11} \mathrm{C}$ are present in NDMC. We accordingly conceived $\mathrm{CNO}$ to be a radioligand yielding the highest contrast of radiosignals for DREADD versus background and compared the in vivo performance of $\left[{ }^{11} \mathrm{C}\right] \mathrm{CNO}$ with $\left[{ }^{11} \mathrm{C}\right]$ CLZ.

PET assays of mice demonstrated the rapid entrance of intravenously injected $\left[{ }^{11} \mathrm{C}\right] \mathrm{CNO}$ to the brain. The radioligand retention was low in the entire brain of WT mice, but was notably increased in the neocortex and hippocampus of hM4Di Tg mice. Unlike the forebrain, the cerebellum exhibited no remarkable differences in the radioactivity retention between the two genotypes (Fig. 2A,B). The target-to-cerebellum ratio of radioactivity after radioligand injection was elevated in the neocortex and hippocampus of Tg but not WT mice over time (Fig. $2 C$ ), resulting in a significant increase of specific radioligand binding to these areas determined as (target-to-cerebellum ratio) - 1 (Fig. 2D). This binding was reduced to a level close to WT mice by pretreatment 


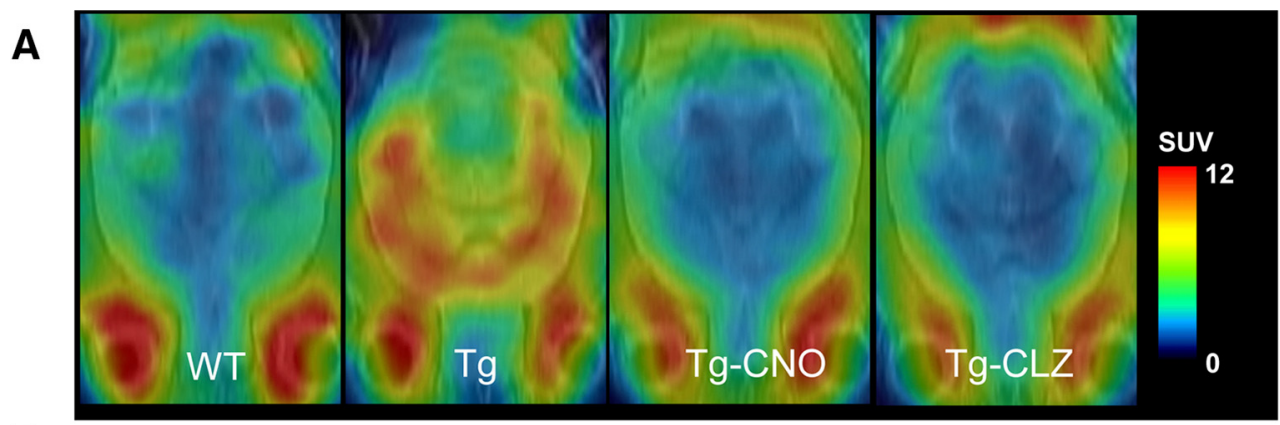

B
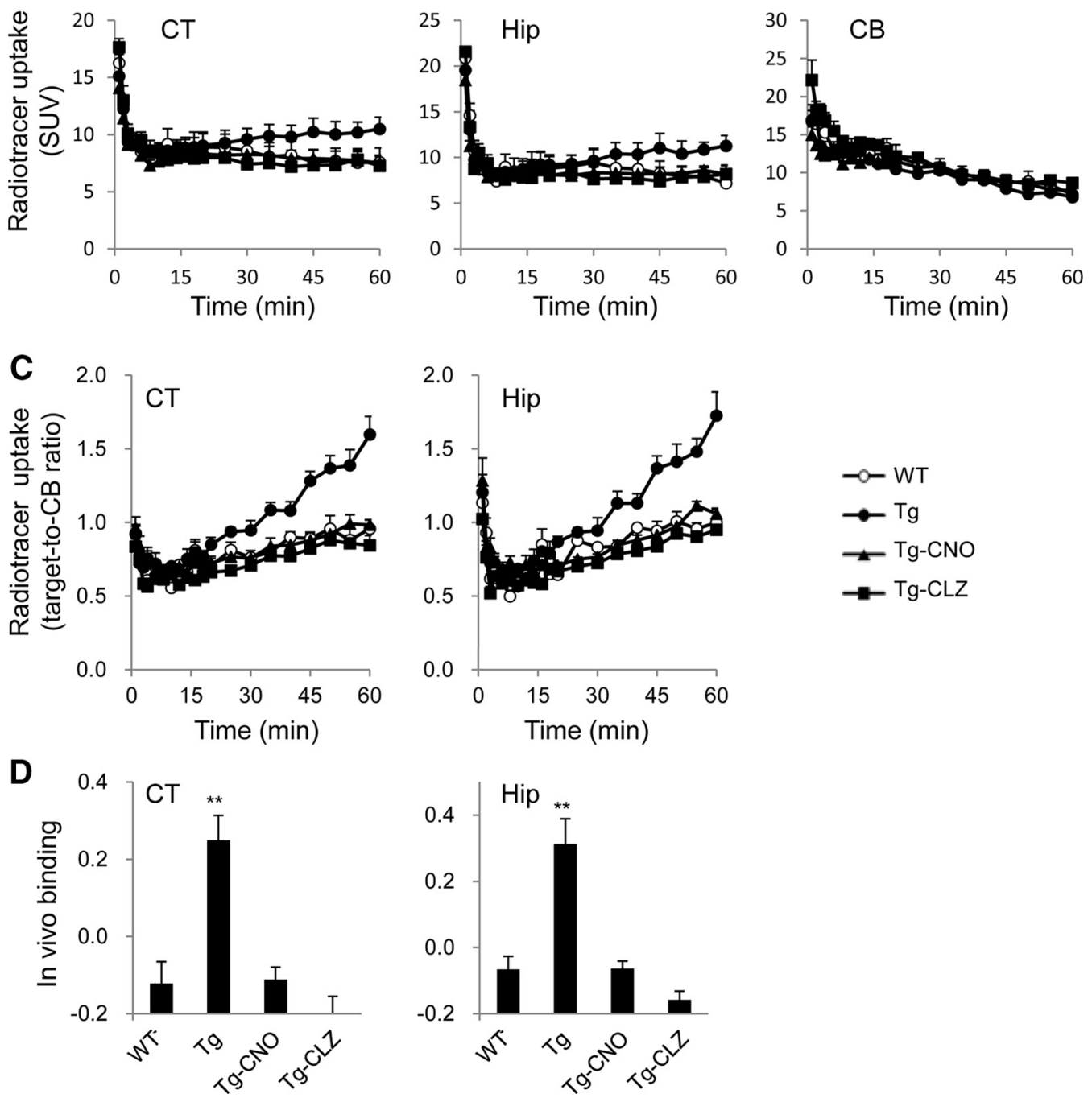

Figure 2. In vivo PET measures in the brains of WT and hM4Di Tg mice after intravenous injection of $\left[{ }^{11} \mathrm{C}\right] C N O$. $A,\left[{ }^{11} \mathrm{C}\right] C N O$ PET imaging in WT and hM4Di Tg mice. The PET images of $\left[{ }^{11} \mathrm{C}\right] C N 0$ generated from averaged dynamic data (30-60 min) are overlapped with the MRI template of mouse horizontal brain sections. From left to right, the images are representative data from WT and hM4Di Tg mice and hM4Di Tg mice pretreated with CNO ( $\mathrm{Tg}-\mathrm{CNO}$ ) and CLZ (Tg-CLZ). Radioligand accumulation in putative Harderian glands was observed around the bottom of each image and was assumed to be nonspecific because it was not blocked by the pretreatments. $B, C,\left[{ }^{11} \mathrm{C}\right] \mathrm{CNO}$ uptake quantified as standardized uptake value (SUV; percentage of injected dose per milliliter tissue $X$ body weight in grams) (B) and target-to-reference ratio of radioactivity $(\boldsymbol{C})$ in the neocortex (CT), hippocampus (Hip), and cerebellum (CB; selected as a reference region) of WT (open circles) and hM4Di Tg (filled circles) mice and hM4Di Tg mice pretreated with CNO (Tg-CNO, filled triangles) and CLZ (Tg-CLZ, filled squares; $n=4-5$ in each group) over the scan time. $\boldsymbol{D}$, In vivo binding of $\left[{ }^{11} \mathrm{C}\right]$ CNO determined as target-to-cerebellum ratio of radioactivity (average of data at $\left.30-60 \mathrm{~min}\right)-1$. There was a significant main effect of group on in vivo binding in $C \mathrm{CT}\left(F_{(3,14)}=13.19, p<\right.$ 0.01 by one-way ANOVA) and $\mathrm{Hip}\left(F_{(3,14)}=15.38, p<0.01\right.$ by one-way ANOVA), and the binding in untreated Tg mice was significantly higher than that in the other three groups $\left({ }^{* *} p<0.01\right.$ by post hoc Bonferroni's test). No statistically significant differences were found between any two of WT, Tg-CNO, and Tg-CLZ groups in either CT or Hip. Error bars indicate SE.

with unlabeled $\mathrm{CNO}$ and CLZ and was accordingly presumed to be saturable and specific for Tg hM4Di (Fig. 2).

Distinct from $\left[{ }^{11} \mathrm{C}\right] \mathrm{CNO}$, a modest increase of radioactivity retention was observed in the forebrain of WT mice relative to the cerebellum after intravenous administration of $\left[{ }^{11} \mathrm{C}\right] \mathrm{CLZ}$ (Fig.
3). The retention in the neocortex and hippocampus was even higher in hM4Di Tg mice (Fig. 3A,B) and the target-to-cerebellum ratio of radioactivity and specific radioligand binding in these regions of Tg mice were increased compared with WT mice (Fig. $3 C, D$ ). The binding of $\left[{ }^{11} \mathrm{C}\right] \mathrm{CLZ}$ to the neocortex and hippocampus 
A
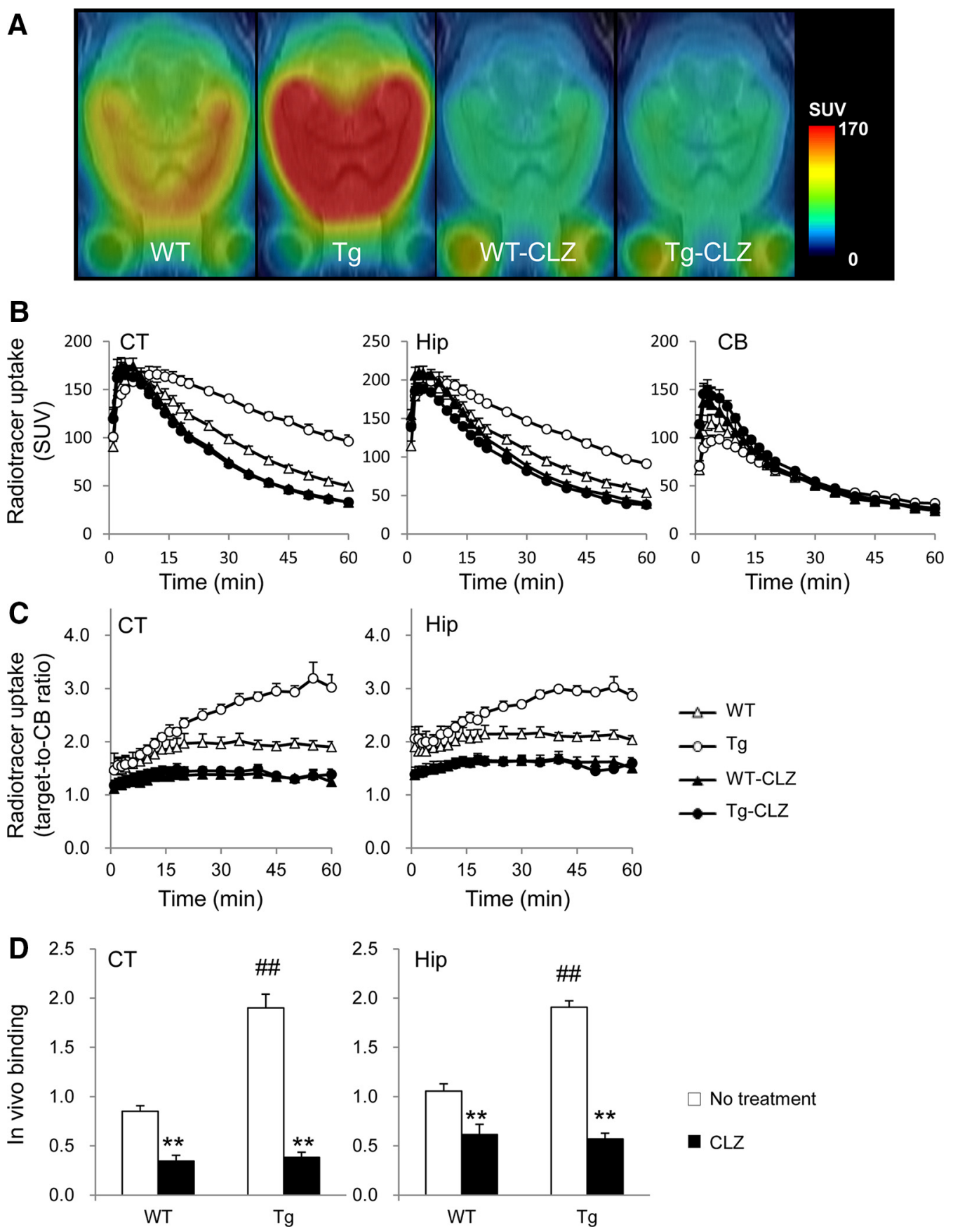

Figure 3. In vivo PET measurements in the brains of WT and hM4Di Tg mice after intravenous injection of $\left[{ }^{11} \mathrm{C}\right] \mathrm{CLZ}$. A, The PET images of $\left[{ }^{11} \mathrm{C}\right] C L Z$ generated by averaging dynamic data at $30-60$ min are overlapped with an MRI template of mouse horizontal brain sections. From left to right, the images are representative of data from WT and hM4Di Tg mice and WT (WT-CLZ) and Tg (Tg-CLZ) mice pretreated with CLZ. B, C, $\left[{ }^{11} \mathrm{C}\right] \mathrm{CLZ}$ uptake expressed as percentage of ID/mI (B) and target-to-reference ratio of radioactivity (C) in the neocortex (CT), hippocampus (Hip), and cerebellum (CB; selected as a reference region) of WT (open triangles) and hM4Di Tg (open circles) mice and CLZ-pretreated WT (WT-CN0, filled triangles) and Tg (Tg-CLZ, filled circles) mice ( $n=4-5$ in each group) over the scan time. $\boldsymbol{D}$, In vivo binding of $\left[{ }^{11} \mathrm{C}\right] \mathrm{CLZ}$ determined as target-to-cerebellum ratio of radioactivity (average of data at $\left.30-60 \mathrm{~min}\right)-1$ for untreated (open columns) and CLZ-pretreated (filled columns) mice. There were significant main effects of the genotype and (LZ pretreatment on in vivo binding in $C \mathrm{~T}\left(F_{(1,12)}=36.57\right.$ and 126.92 , respectively, $p<0.01$ by two-way ANOVA) and Hip $\left(F_{(1,12)}=18.69\right.$ and 90.62 , respectively, $p<0.01$ by two-way ANOVA). In both regions, the binding in untreated Tg mice was significantly higher than that in WT mice (\#p $<0.01$ by post hoc Bonferroni's test) and (LZ pretreatment decreased the binding significantly in both genotypes (** $p<0.01$ by post hoc Bonferroni's test). Error bars indicate SE.

of WT and Tg mice was suppressed significantly by pretreatment with unlabeled CLZ, suggesting that this ligand reacts specifically with hM4Di and endogenous murine components (Fig. 3). Together, these observations supported the superiority of $\left[{ }^{11} \mathrm{C}\right] \mathrm{CNO}$ over $\left[{ }^{11} \mathrm{C}\right] \mathrm{CLZ}$ for high-contrast imaging of hM4Di with minimal background signals in a mouse model.

Unlike in vivo PET imaging, in vitro autoradiographic labeling of mouse brain sections with $\left[{ }^{11} \mathrm{C}\right] \mathrm{CNO}$ and $\left[{ }^{11} \mathrm{C}\right] \mathrm{CLZ}$ was un- successful due to low specificity and intense background (data not shown) and therefore subregional localization of radioligand binding remains undetermined.

DREADD-mediated manipulation of neuronal activity in $\mathrm{Tg}$ mouse brains

We then assessed the capability of the DREADD-CNO system to control neuronal activities without stimulating endogenous 
A

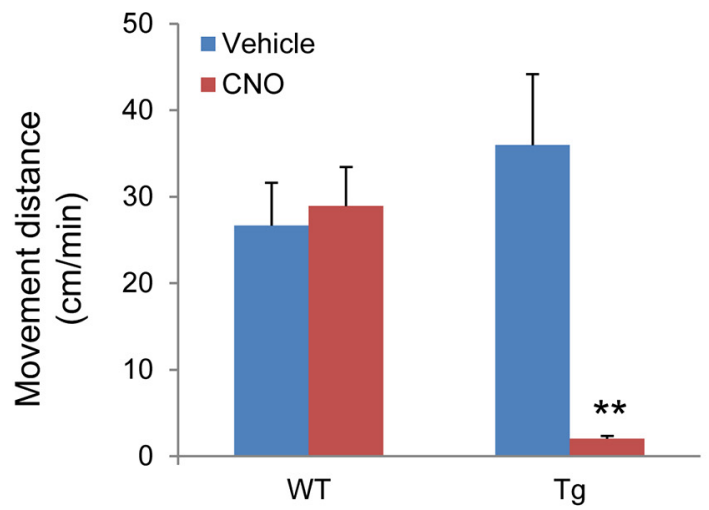

B

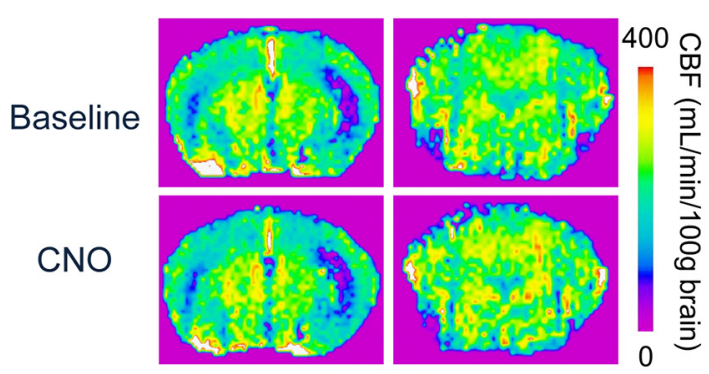

D

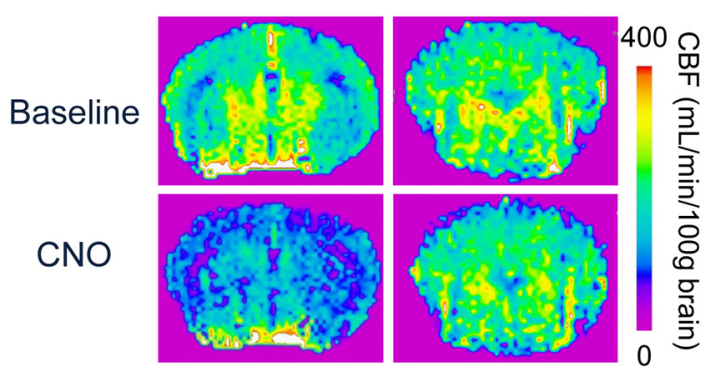

\section{C}

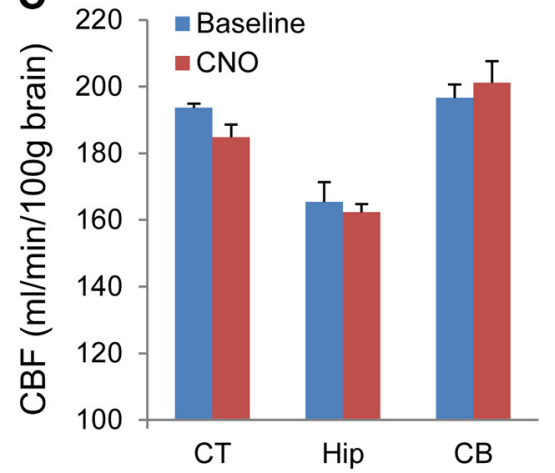

E

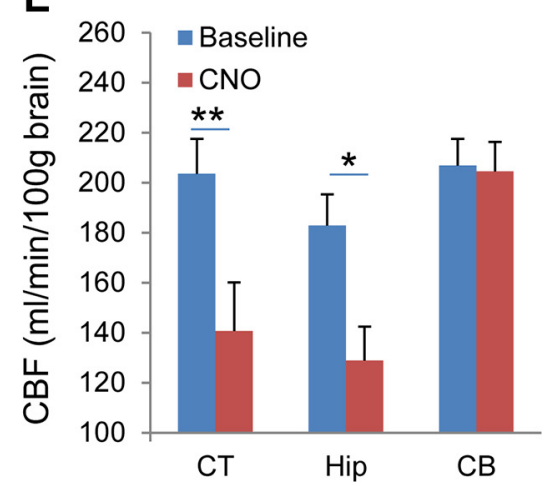

Figure 4. Neuronal silencing exclusively induced by CNO in hM4Di Tg mice. A, Locomotor activity was evaluated by measuring the distance moved by WT and hM4Di Tg mice administered vehicle or CNO before assessments ( $n=6$ per group). There was a significant main effect of $\mathrm{CNO}$ administration $\left(F_{(1,20)}=7.5, p<0.05\right.$ by two-way ANOVA), but not genotype of animals $\left(F_{(1,20)}=2.34\right.$, $p>0.05$ by two-way ANOVA). However, a significant interaction between these two parameters was observed ( $p<0.01$ by two-way ANOVA). Post hoc analysis revealed a significant decrease in locomotor activity in CNO-treated Tg mice compared with control Tg or CNO-treated WT mice (** $p<0.01$, Bonferroni), but no significant difference was observed between control and CN0-treated WT mice ( $p>0.05$, Bonferroni). $\boldsymbol{B}-\boldsymbol{E}$, Assessment of neuronal activity by ASL-MRI. Top and bottom demonstrate representative brain images at baseline and after administration of CNO, respectively, in WT $(\boldsymbol{B})$ and hM4Di $\mathrm{Tg}(\boldsymbol{D})$ mice. Left and right represent coronal sections at $-1.9 \mathrm{~mm}$ and $-6.6 \mathrm{~mm}$ anterior to the bregma mainly containing the neocortex/hippocampus and cerebellum regions, respectively. Quantitative analyses of CNO-induced CBF changes in WT $(n=3)$ and hM4Di Tg $(n=5)$ mice are shown in Cand $\boldsymbol{E}$, respectively. In WT mice, there was a significant main effect of region $\left(F_{(1,24)}=22.91, p<0.01\right.$ by two-way ANOVA) but not CN0 treatment $\left(F_{(1,24)}=0.313, p>0.05\right.$ by two-way ANOVA) on (BF measures. No interaction between these two parameters was found ( $p>0.05$ by two-way ANOVA) and post hoc analyses did not indicate any significant difference in (BF between baseline and CNO treatment ( $p>0.05$ by Bonferroni's test). In Tg mice, there were significant main effects of CNO administration $\left(F_{(1,24)}=9.70, p<0.01\right.$ by two-way ANOVA) and region $\left(F_{(2,24)}=5.30, p<0.05\right)$ on $C B F$ measures. CBF was decreased significantly in the neocortex (CT) and hippocampus (Hip), but not in the cerebellum (CB), after CN0 administration in hM4Di Tg mice ( ${ }^{*} p<0.05$, ${ }^{* *} p<0.01$, by Bonferroni's test for multiple comparisons after ANOVA, compared with baseline in corresponding regions), whereas (NO administration had no significant effect on CBF in any assayed regions in WT mice. Error bars indicate SE.

mAChR signaling pathways. WT and hM4Di Tg mice presented similar locomotive activity in an open field, whereas intraperitoneal injection of $1 \mathrm{mg} / \mathrm{kg}$ CNO induced immobilization of hM4Di Tg mice, in contrast to the absence of behavioral alterations in WT mice (Fig. 4A).

Effects of $\mathrm{CNO}$ on regional neuronal activities in hM4Di Tg mice were examined by ASL-MRI. This technology enables quantitative mapping of local brain activities based on neurovascular coupling mechanisms (Smith et al., 2002) and has been demon- strated to detect changes in activation-related CBF with high reproducibility and spatial accuracy (Raoult et al., 2011). Indeed, $\mathrm{CBF}$ was profoundly decreased in forebrain regions of hM4Di Tg mice after the intravenous administration of $1 \mathrm{mg} / \mathrm{kg}$ unlabeled $\mathrm{CNO}$, but no $\mathrm{CBF}$ alterations were observed in the cerebellum of these animals (Fig. 4D,E). The distribution of CNO-induced CBF suppression in Tg mice was in good agreement with the spatial extent of Tg hM4Di expression. In WT mice, the administration of CNO did not result in noticeable changes in CBF (Fig. 

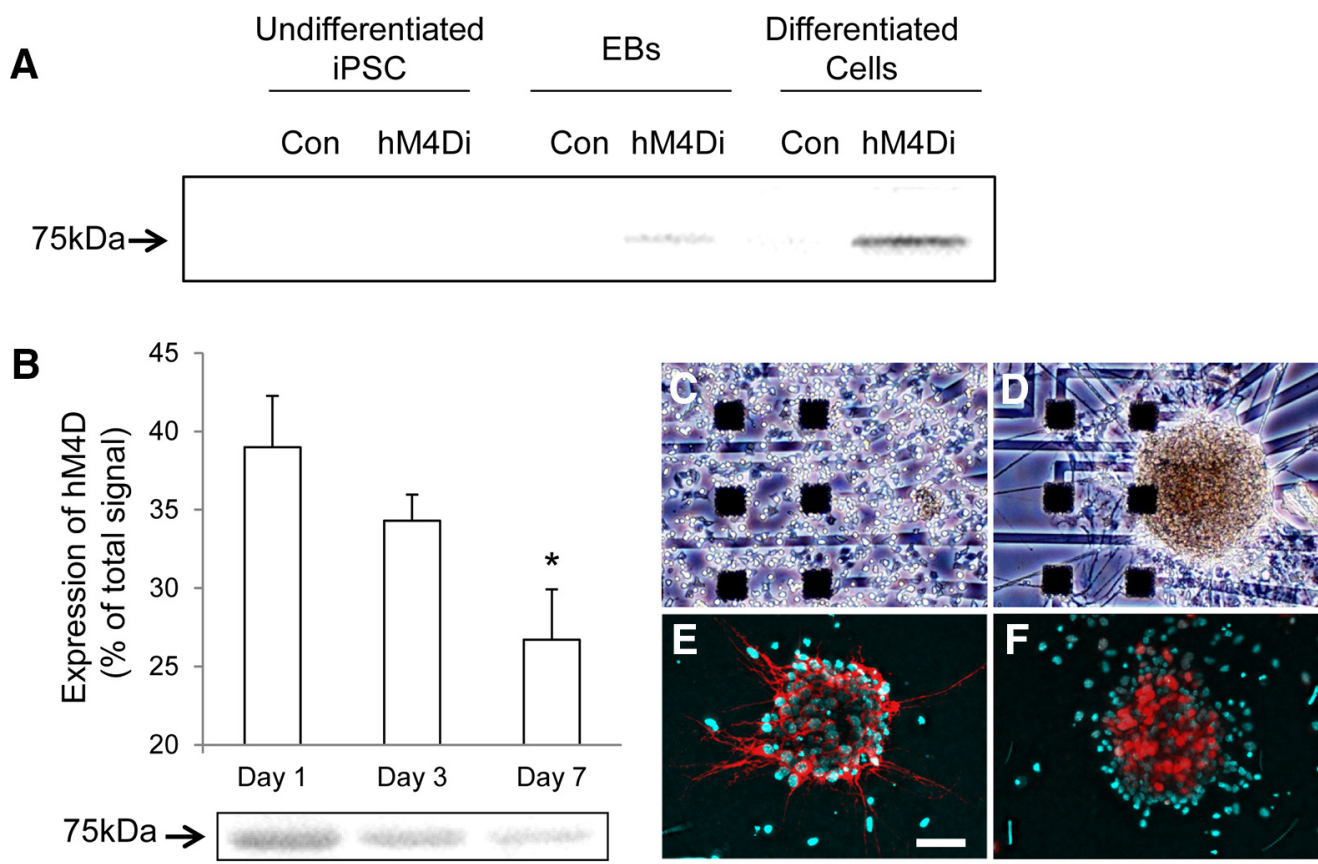

G

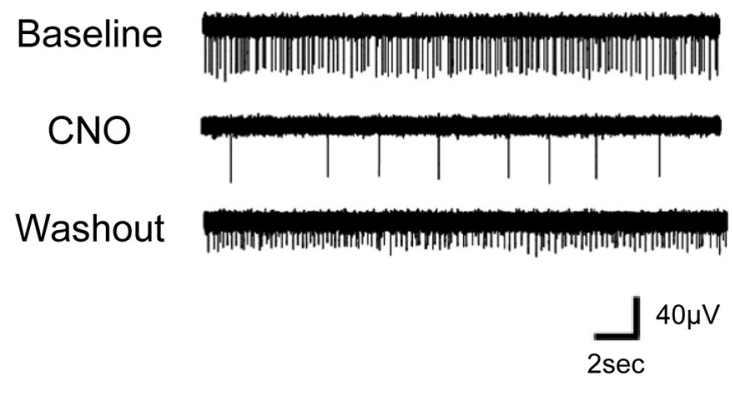

H

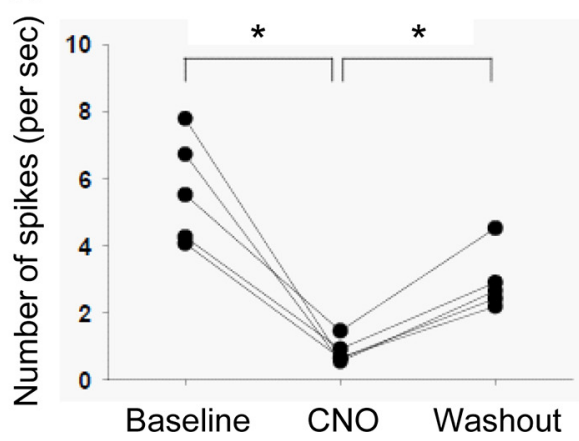

Figure 5. In vitro neuronal differentiation and functionality of hM4Di-iPSC-derived cells. $\boldsymbol{A}$, Western blot analysis for hM4Di expression with a newly developed original antibody in undifferentiated iPSCs, EBs, and differentiated cells (1 d after seeding) from DsRed-iPSC (negative control) and hM4Di-iPSC. The blot is representative of 5 control and hM4Di Tg samples at each time point. $\boldsymbol{B}$, Semiquantitative Western blot analysis of the hM4Di expression in hM4Di-iPSC-derived neuronal cells at different time points. hM4Di expression was detected quantitatively with our original antibody (normalized as a percentage of total signal density; $n=5$ per group). There was a significant main effect of the time point on the $h M 4 D i$ expression $\left(F_{(2,12)}=4.84, p<0.05\right.$ by one-way ANOVA). Post hoc analysis revealed that hM4Di expression was significantly decreased at day 7 relative to day $1\left({ }^{*} p<0.05\right.$, Bonferroni). A representative image of Western blotting is also displayed (bottom). $\boldsymbol{C}-\boldsymbol{F}$, Bright-field microscopic observations at $0(\boldsymbol{C})$ and $14(\boldsymbol{D})$ days and two-channel fluorescence $(\boldsymbol{E}, \boldsymbol{F})$ after seeding of cells dissociated from iPSC-derived EBs on a MED64 Prove Dish. Nuclear staining (DAPl; cyan in $\boldsymbol{E}, \boldsymbol{F}$ ) and immunostaining of markers for neuronal cells (MAP2; red in $\boldsymbol{E}$, NeuN; red in $\boldsymbol{F}$ ) in neurosphere-like clusters of cells at $14 \mathrm{~d}$ demonstrated that the majority of these cells had differentiated to mature neurons. $\mathbf{G}, \boldsymbol{H}$, Representative electrographs showing neuronal firing of hM4Di-iPSC cells in a cluster at $14 \mathrm{~d}$ after seeding at baseline, after addition of CN0 $(1 \mu \mathrm{M})$, and after washout of CNO with CNO-free fresh medium (G). Quantitative analysis is shown in $\boldsymbol{H}\left(n=5\right.$ in each group; $F_{(2,4)}=23.9, p<0.01$ by one-way, repeated-measures ANOVA; ${ }^{*} p<$ 0.05 for the difference between baseline and CNO treatment and between CNO treatment and washout by post hoc Bonferroni's test). Spikes larger than a voltage threshold of $25 \mu \mathrm{V}$ were counted. Error bars indicate SE. Scale bar, $150 \mu \mathrm{m}(\boldsymbol{C}-\boldsymbol{F})$.

$4 B, C)$, supporting the view that $\mathrm{CNO}$ at this dosage does not functionally modify endogenous mAChRs. These findings provide evidence that ASL-MRI could capture sensitively the neuronal silencing resulting from selective stimulation of hM4Di by $\mathrm{CNO}$ in vivo.

\section{CNO-induced electrophysiological repression of neurons differentiated from hM4Di Tg iPSCs}

We established a line of iPSCs derived from embryonic fibroblasts of a hM4Di Tg mouse. These cells (hM4Di-iPSCs) were subsequently cultured in a suspension of serum-free medium to form EBs enriched with neural progenitors. Further adherent culture of enriched polysialic acid-neural cell adhesion moleculepositive (PSA-NCAM+) cells resulted in the generation of doublecortin-positive immature neurons at $1-3 \mathrm{~d}$ and these cells were then differentiated into mature neurons with decreased doublecortin immunoreactivity and increased positivity for MAP2 and NeuN within $7 \mathrm{~d}$ of seeding (data not shown).

Although H-175 failed to produce specific immunoblots of hM4Di (data not shown), our original antibody against human M4 mAChR offered a Western blot analysis of hM4Di expression along the course of neuronal culture. The levels of hM4Di expression were below the detection threshold in undifferentiated hM4Di-iPSCs and became detectable when these cells formed EBs. The expression of hM4Di peaked within $3 \mathrm{~d}$ of adherent culture and persisted at $7 \mathrm{~d}$ despite its significant decrease from the initial level (Fig. 5A,B).

The functionality of hM4Di expressed in mature neuronal culture was investigated using the MED64 multielectrode recording system. PSA-NCAM+ cells isolated from EBs were scattered 
on a MED64 multielectrode recording dish at seeding and gathered to form a spherical cluster while extending neuritic processes along the course of neuronal differentiation (Fig. $5 C, D$ ). The majority of these clustered cells displayed neuronal markers such as MAP2 and NeuN (Fig. $5 E, F$ ). The application of $1 \mu \mathrm{M} C N O$ to the dish reduced spike frequency dramatically in these cells and this suppression was reversed by withdrawal of CNO (Fig. 5G,H).

These in vitro observations support the possibility of chemogenetically and reversibly silencing activities of hM4Di-iPSCderived neurons via the DREADD-CNO system when they are implanted in the brain.

\section{In vivo visualization of neuronal differentiation and functional modulation of iPSC-derived implants expressing hM4Di}

Implantation of neural progenitors into the WT mouse hippocampus was first conducted using EBs derived from iPSCs constitutively expressing fluorescent protein DsRed (DsRed-iPSCs) under the control of a universal promoter to analyze the identities of surviving grafts after the animals were killed. Fluorescence microscopic examinations of brains collected $20 \mathrm{~d}$ after grafting revealed clusters of transplanted cells intensified in the hilus of the unilateral hippocampus, as well as differentiation of the implants into mature neurons and astrocytes, but not microglia (Fig. 6). These cells with clear cellular phonotypes coexisted with a portion of $\operatorname{DsRed}(+)$ but $\mathrm{NeuN}(-)$ round cell bodies, which were conceived as poorly differentiated progenitors or oligodendrocytes (Fig. $6 D-F$, arrows). The graft cells were consolidated in the unilateral dorsal hippocampus and adjacent subcortical white matter, but their processes were extended to distant locations such as the ipsilateral ventral and contralateral dorsal hippocampi, as monitored by DsRed immunostaining (Fig. 7). Notably, intense bundles of DsRedpositive fibers were observed along the ipsilateral subcortical white matter tract (Fig. 7), illustrating the propensity of graft neurites to track a preexisting axonal path. These fibrous structures were observed in areas distant from the implantation site at the hippocampal hilus/CA3 and were morphologically distinct from migrating glial cells, excluding the possibility that they were debris of dead grafts bearing DsRed.

Longitudinal $\left[{ }^{11} \mathrm{C}\right] \mathrm{CNO}-\mathrm{PET}$ scans of WT mice after intrahippocampal implantation of DsRed-iPSC-derived neural progenitors demonstrated no detectable changes in radioactive signals over the observation period up to $60 \mathrm{~d}$ (Fig. $8 \mathrm{~A}, E$ ). We then grafted hM4Di-iPSC-derived neural progenitors to the unilateral hippocampus of WT mice for in vivo neuroimaging assays. $\left[{ }^{11} \mathrm{C}\right] \mathrm{CNO}-\mathrm{PET}$ measurements showed no marked alterations at $20 \mathrm{~d}$ after implantation (Fig. $8 B, E$ ), but demonstrated a significant increase of radioligand retention in the ipsilateral hippocampus relative to the corresponding contralateral area at $40 \mathrm{~d}$ (Fig. $8 C, E$ ). The grafts were still visible by PET at $60 \mathrm{~d}$ despite considerable decline of signals at the implantation site from the level at $40 \mathrm{~d}$ (Fig. $8 D, E$ ). We also performed PET scans of these mice with $\left[{ }^{11} \mathrm{C}\right] \mathrm{CLZ}$, but, unlike $\left[{ }^{11} \mathrm{C}\right] \mathrm{CNO}$, there was no pronounced difference in radioligand retention between ipsilateral and contralateral hippocampi at $40 \mathrm{~d}$ (data not shown).

Consistent with the in vivo PET data, postmortem investigations of the WT mouse brains sampled at $40 \mathrm{~d}$ after the implantation of DsRed-iPSC-derived neural progenitors showed no overt H-175 immunoreactivity in grafted cells illuminated by DsRed (Fig. 8F,G), whereas abundant $\mathrm{H}-175$ signals seemingly from hM4Di-expressing grafts were present in the implantation site at $40 \mathrm{~d}$ (Fig. $8 \mathrm{H}$ ). Double immunofluorescence staining also revealed that $\mathrm{H}-175$ staining colocalized or coexisted with $\mathrm{NeuN}$ in single cells (Fig. 8I-K), but did not overlap with an astrocytic marker, glial fibrillary acidic protein (GFAP; Fig. $8 L-N$ ). Therefore, PET signals are attributable to an abundant expression of hM4Di in mature neurons differentiated from the grafts.

In addition to PET visualization, the functional operability of hM4Di-expressing implants was examined by ASL perfusion MRI in a mouse at $40 \mathrm{~d}$ after grafting. Comparative antemortem T2weighted MRI and postmortem microscopic assays allowed mapping of grafts implanted into the unilateral hippocampal hilus (Fig. $9 A, B)$. Indeed, immunohistochemistry of a coronal mouse brain slice with the antibody $\mathrm{H}-175$, which recognizes endogenous M4 $\mathrm{mAChR}$ and hM4Di, demonstrated a cluster of immunolabeling signals derived from implants in the injection site at the hilus and a part of CA3 (Fig. 9A, white arrow), in sharp contrast to the sparse stains in the contralateral counterpart (cf. Fig. $9 F, G$ ). Correspondingly, the injection site was indicated as the tip of the needle tract located around the hippocampal hilus in MRI of the same mouse (Fig. 9B). Although no noticeable changes in CBF were induced by intravenous administration of $1 \mathrm{mg} / \mathrm{kg} \mathrm{CNO}$ as assessed by ASLMRI at $20 \mathrm{~d}$ after implantation (data not shown), CNO treatment resulted in significant suppression of CBF in the ipsilateral CA1 and hilus/CA3 sectors relative to pretreatment baseline at $40 \mathrm{~d}$ (Fig. 9C$E$ ). In light of these data, it is likely that graft neurons in the hilus/CA3 had connection with neighboring host neurons projecting to CA1 via Schaffer collateral or extended their own processes along this tract to innervate CA1 host neurons directly. In contrast, CBF measures in other areas, including the ipsilateral and contralateral ventral neocortex and thalamus, did not change in response to the $\mathrm{CNO}$ treatment (data not shown). Surgery-associated deformity in the dorsal neocortex impeded the quantification of $\mathrm{CBF}$ in this region. Together, our results demonstrate the functional modulation of PET-visible neuronal implants and their direct and/or indirect projection site by systemically injected CNO.

\section{Discussion}

The present work has provided evidence for the dual utility of DREADD as a PET-visible reporter of CNS gene expression, as well as a chemogenetic controller of a specific group of nervous cells. The gene construct containing hM4Di downstream of a neuron-specific Thy-1 promoter allowed long-term monitoring of the differentiation of iPSC-derived implants to mature neurons in living mouse brains and offered a method to modulate reversibly the activity of the grafts per se and the connecting host neurons. It is noteworthy that the detectability of graft hM4Di by PET was coupled chronologically with the functional operability of the neuronal graft by $\mathrm{CNO}$. Indeed, $\mathrm{CNO}$ induced no local CBF changes at $20 \mathrm{~d}$ after the implantation of hM4Di-iPSCderived cells, notwithstanding the massive fibers growing from the implants and terminating in close contact to resident neurons at this stage. This was in distinct contrast to the overt repression of $\mathrm{CBF}$ in the ipsilateral hippocampus after $\mathrm{CNO}$ injection at $40 \mathrm{~d}$. Correspondingly, hM4Di-expressing implants were not detectable by $\left[{ }^{11} \mathrm{C}\right] \mathrm{CNO}-\mathrm{PET}$ at $20 \mathrm{~d}$, but could be captured by the same imaging assay at $40 \mathrm{~d}$. In this context, the PET visibility of hM4Di is an indicator for the functional controllability of grafts expressing this DREADD. hM4Di-associated PET signals were maximized at $40 \mathrm{~d}$ and decreased thereafter. This might reflect massive neuronal death during the construction of neural networks, an event also observed under physiological conditions, for removing the superfluous neuronal cells presumably by glial cells. This mechanism may not be recapitulated by an in vitro culture system that contains no glial populations and forms no mature networks. In fact, in vitro 

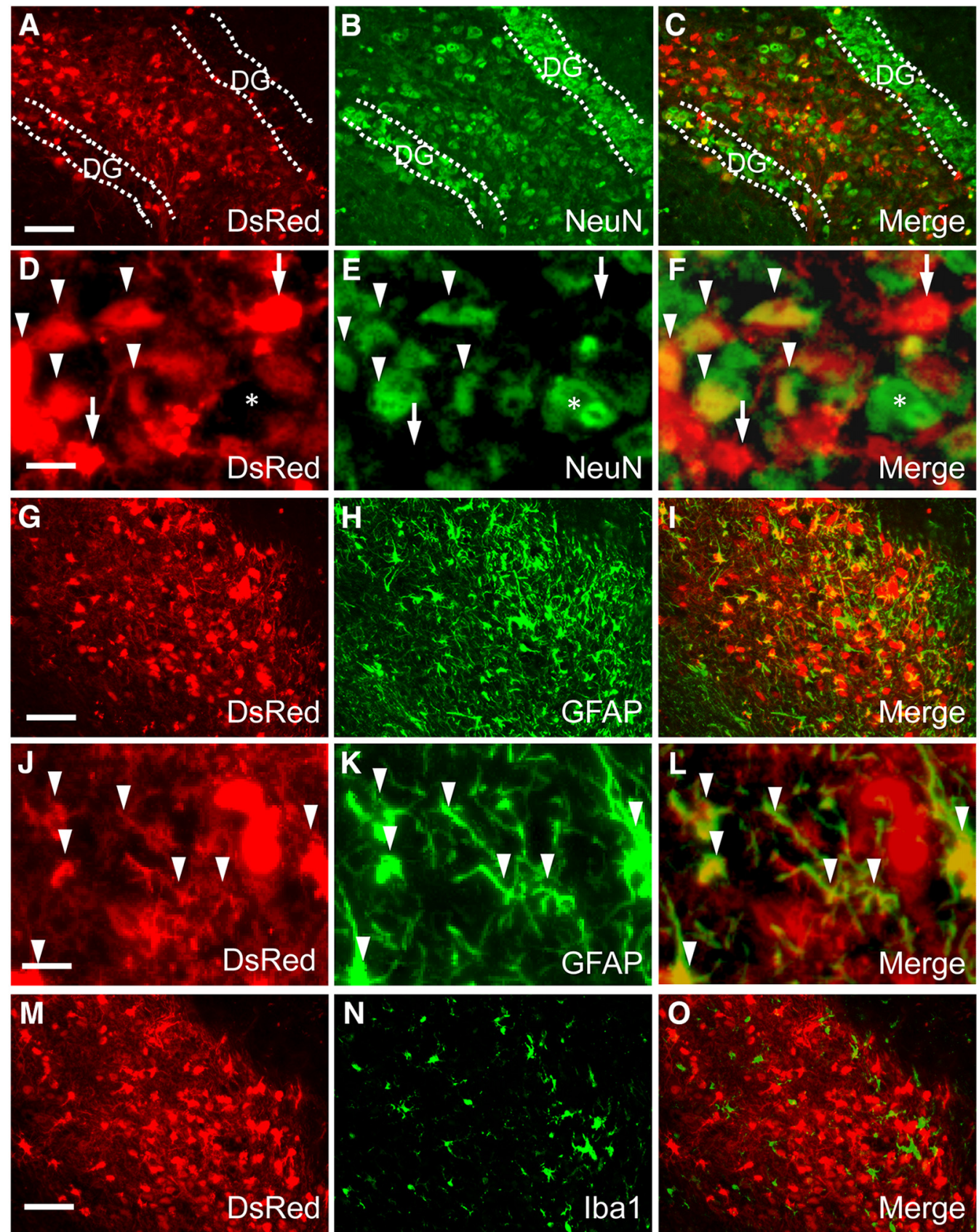

Figure 6. In vivo neural differentiation of DsRed-iPSC-derived cells at $20 \mathrm{~d}$ after implantation in adult mouse brain. $\boldsymbol{A}-\boldsymbol{F}$, Two-channel photomicrographs of DsRed fluorescence $(\boldsymbol{A}, \boldsymbol{D}$, and red in $\boldsymbol{C}, \boldsymbol{F})$ and immunofluorescence staining of $\operatorname{NeuN}(\boldsymbol{B}, \boldsymbol{E}$, and green in $\boldsymbol{C}, \boldsymbol{F})$ demonstrated that a significant portion of implanted cells had differentiated into mature neurons. In low-power images $(\boldsymbol{A}-\boldsymbol{C})$, injected transplants were intensely clustered in the hippocampal hilus flanked by dentate granule cells (DG). High-power images $(\boldsymbol{D}-\boldsymbol{F})$ illustrate the coexistence of DsRed $(+)$ grafted iPSC-derived (arrowheads) and DsRed(-) endogenous (asterisks) neurons among NeuN $(+)$ cells. There also existed NeuN $(-)$, DsRed(+) large cell bodies originating from transplanted progenitors ( $\boldsymbol{D}-\boldsymbol{F}$, arrows), which could be either oligodendrocytes or undifferentiated species. $\mathbf{G}-\boldsymbol{L}$, Two-channel photomicrographs of DsRed fluorescence $(\boldsymbol{G}, \boldsymbol{J}$, and red in $\boldsymbol{I}, \boldsymbol{L})$ and immunofluorescence staining of GFAP $(\boldsymbol{H}, \boldsymbol{K}$, and green in $\boldsymbol{I}, \boldsymbol{L})$ showing that a subset of implanted cells exhibited astrocytic phenotype (arrowheads). $\boldsymbol{M}$ - $\mathbf{0}$, Two-channel photomicrographs of DsRed fluorescence $(\boldsymbol{M}$ and red in $\boldsymbol{O})$ and immunostaining of Iba1 ( $\boldsymbol{N}$ and green in $\boldsymbol{O}$ ) indicated that implanted cells were not able to differentiate into microglia. The images are representative of 5 mice. Scale bars: (A-C, $\mathbf{G}-\mathbf{I}, \mathbf{M}-\mathbf{0}, 100 \mu \mathrm{m} ; \mathbf{D}-\boldsymbol{F}, \mathbf{J}-\mathbf{L}, 20 \mu \mathrm{m}$.

results showed a greatly different time course of hM4Di expression peaking at $1-3 \mathrm{~d}$ after the seeding of neuronal progenitors.

Interestingly, $\left[{ }^{11} \mathrm{C}\right] \mathrm{CLZ}-\mathrm{PET}$ was not able to visualize hM4Di expressions in iPSC-derived cells despite the high brain uptake and specific binding of $\left[{ }^{11} \mathrm{C}\right]$ CLZ in Tg mice. A key property of $\left[{ }^{11} \mathrm{C}\right] \mathrm{CNO}$ was the very low affinity of this compound for nonmutant $\mathrm{mAChR}$, as indicated in a previous in vitro assessment (Nawaratne et al., 2008). Indeed, retention of $\left[{ }^{11} \mathrm{C}\right] \mathrm{CNO}$ in the forebrain of a WT mouse was lower than the cerebellar values
(Fig. 2C,D), notwithstanding the presence and absence of $\mathrm{mAChR}$ in the forebrain and cerebellum, respectively (Fig. 1C). As a consequence, the $\mathrm{Tg}$ mouse forebrain displayed 2 -fold higher target-to-cerebellum ratios of radioactivity than the WT forebrain at $60 \mathrm{~min}$ after $\left[{ }^{11} \mathrm{C}\right] \mathrm{CNO}$ injection (Fig. $2 \mathrm{C}$ ). These ratios in the Tg mouse forebrain were 1.5-fold higher than those in the WT mouse forebrain at $60 \mathrm{~min}$ after $\left[{ }^{11} \mathrm{C}\right] \mathrm{CLZ}$ injection (Fig. 3C). Based on these observations, the target-to-cerebellum ratios of $\left[{ }^{11} \mathrm{C}\right] \mathrm{CLZ}$ retention in the grafted hippocampus were 
estimated to be $15 \%$ higher than those in the contralateral control if these ratios of $\left[{ }^{11} \mathrm{C}\right] \mathrm{CNO}$ retention in the ipsilateral side were $30 \%$ higher than those in the contralateral side, which is relevant to the data shown in Figure $8 E$. Given that the testretest variability of these ratios was $10-$ $15 \%$, it can be assumed that hM4Di expression in the implants may not be detectable robustly by $\left[{ }^{11} \mathrm{C}\right] \mathrm{CLZ}-\mathrm{PET}$.

Although $\left[{ }^{11} \mathrm{C}\right] \mathrm{CNO}-\mathrm{PET}$ was suitable for capturing a relatively small amount of hM4D in the mouse brain, the lower uptake of $\left[{ }^{11} \mathrm{C}\right] \mathrm{CNO}$ in the brain than that of $\left[{ }^{11} \mathrm{C}\right] \mathrm{CLZ}$ might hamper sensitive detection of hM4Di if the sensitivity of the PET imaging device and the injected radioactivity dose of the radioligand per body weight are limited. In fact, our pilot study has implied that $\left[{ }^{11} \mathrm{C}\right] \mathrm{CLZ}$ might perform better than $\left[{ }^{11} \mathrm{C}\right] \mathrm{CNO}$ in visualizing the viral-vectormediated expression of hM4Di in the brain of a rhesus monkey with the current Focus220 scanner (Y. Nagai, E. Kikuchi, W. Lerchner, K. Inoue, B. Ji, M. Eldridge, H. Kaneko, Y. Kimura, A. Oh-Nishi, Y. Hori, Y. Kato, T. Hirabayashi, A. Fujimoto, K. Kumata, M.-R. Zhang, I. Aoki, T. Suhara, M. Higuchi, M. Takada, B.J. Richmond, and T. Minamimoto, unpublished data). The transfer of $\left[{ }^{11} \mathrm{C}\right] \mathrm{CNO}$ through BBB is likely to be impeded by polarity at the $N$-oxide portion of this compound, which could provide superior selectivity for DREADD. Efflux transporters residing at cerebral vasculature might also affect the trans-BBB permeability of $\left[{ }^{11} \mathrm{C}\right] \mathrm{CNO}$, but our preliminary PET assays indicated that uptake of $\left[{ }^{11} \mathrm{C}\right] \mathrm{CNO}$ in the brain of rats deficient of P-glycoprotein/Mdrla (SAGE Laboratories) did not differ from values in WT controls (data not shown). For improving the applicability of a DREADD radioligand to diverse animal species, we are currently characterizing newly generated $\mathrm{CNO}$ analogs, although alkylation of nitrogen in a tricyclic structure to increase lipophilicity was found to be ineffective for improving the image contrast of hM4Di in mouse and monkey brains (B. Ji, M.-R. Zhang, K. Kumata, Y. Nagai, T. Suhara, B.J. Richmond, T. Minamimoto, and M. Higuchi, unpublished data).

A target-to-reference ratio of radioactivity, which reflects specific binding of $\left[{ }^{11} \mathrm{C}\right] \mathrm{CNO}$, presented a progressive increase during the PET imaging time (Fig. $2 \mathrm{~B}, \mathrm{C}$ ). This property of $\left[{ }^{11} \mathrm{C}\right] \mathrm{CNO}$ impeded the determination of a nondisplaceable binding potential of this radioligand based on a reversible binding model such as the simplified reference tissue model (Lammertsma et al., 1996), so we used (target-to-reference ratio of radioactivity) -1 at 30-60 min as a provisional and simplified index for radioligand binding. The continuous increase of radioactivity retention in the target area over $60 \mathrm{~min}$ may be attributed to slowly reversible or irreversible binding of $\left[{ }^{11} \mathrm{C}\right] \mathrm{CNO}$ to hM4Di. In addition, it cannot be ruled out that radio-
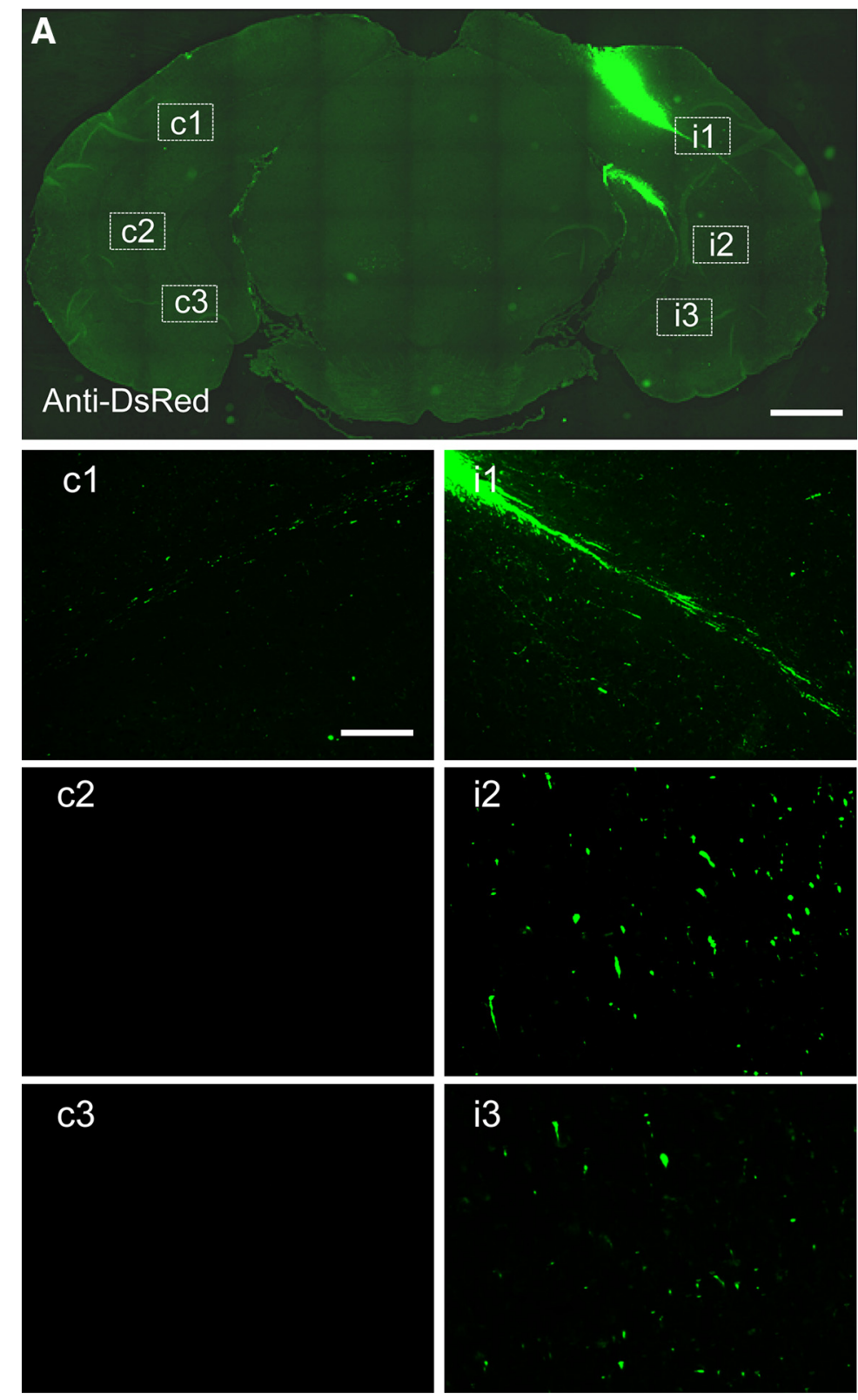

Figure 7. Extension of axon-like processes from intracranially implanted DsRed-iPSC-derived EBs in adult mouse brain. Immunohistochemical analyses with an anti-DsRed antibody at low power showed that DsRed-iPSC-derived exogenous grafts were white dotted lines in contralateral ( $\mathbf{c} \mathbf{1 - C 3})$ and ispilateral (i1-i3) subcortical white matter tracts are shown in separate images. The images are representative of 5 mice. Scale bar: $A, 1 \mathrm{~mm} ; \mathbf{c} 1-\mathbf{c}_{3}, \mathbf{i 1}-\mathbf{i} \mathbf{3}, 100 \mu \mathrm{m}$.

active metabolites of $\left[{ }^{11} \mathrm{C}\right] \mathrm{CNO}$ were produced in the periphery and gradually entered the brain to react with hM4Di. A potential major radiometabolite of $\left[{ }^{11} \mathrm{C}\right] \mathrm{CNO}$ could be $\left[{ }^{11} \mathrm{C}\right] \mathrm{CLZ}$, in light of an earlier report on metabolites of $\mathrm{CNO}$ in rat urines at $0-24 \mathrm{~h}$ after oral administration of CNO (Lin et al., 1996). However, urinary CLZ and other metabolites were $\sim 15$-fold less abundant than $\mathrm{CNO}$ (Lin et al., 1996) and a more recent study indicated very little conversion of CNO to CLZ in mouse plasma over 120 min after intraperitoneal injection of CNO (Guettier et al., 2009). Quantification of radiometabolites of $\left[{ }^{11} \mathrm{C}\right] \mathrm{CNO}$ in mouse brain and plasma after intravenous radioligand injection at a microdose will need to be performed carefully by minimizing the artificial generation of $\left[{ }^{11} \mathrm{C}\right] \mathrm{CLZ}$ by reduction of $\left[{ }^{11} \mathrm{C}\right] \mathrm{CNO}$ during sampling and measurements and by considering the substantial difference in the plasma-free fraction 


\section{DsRed-iPSC}

hM4Di-iPSC
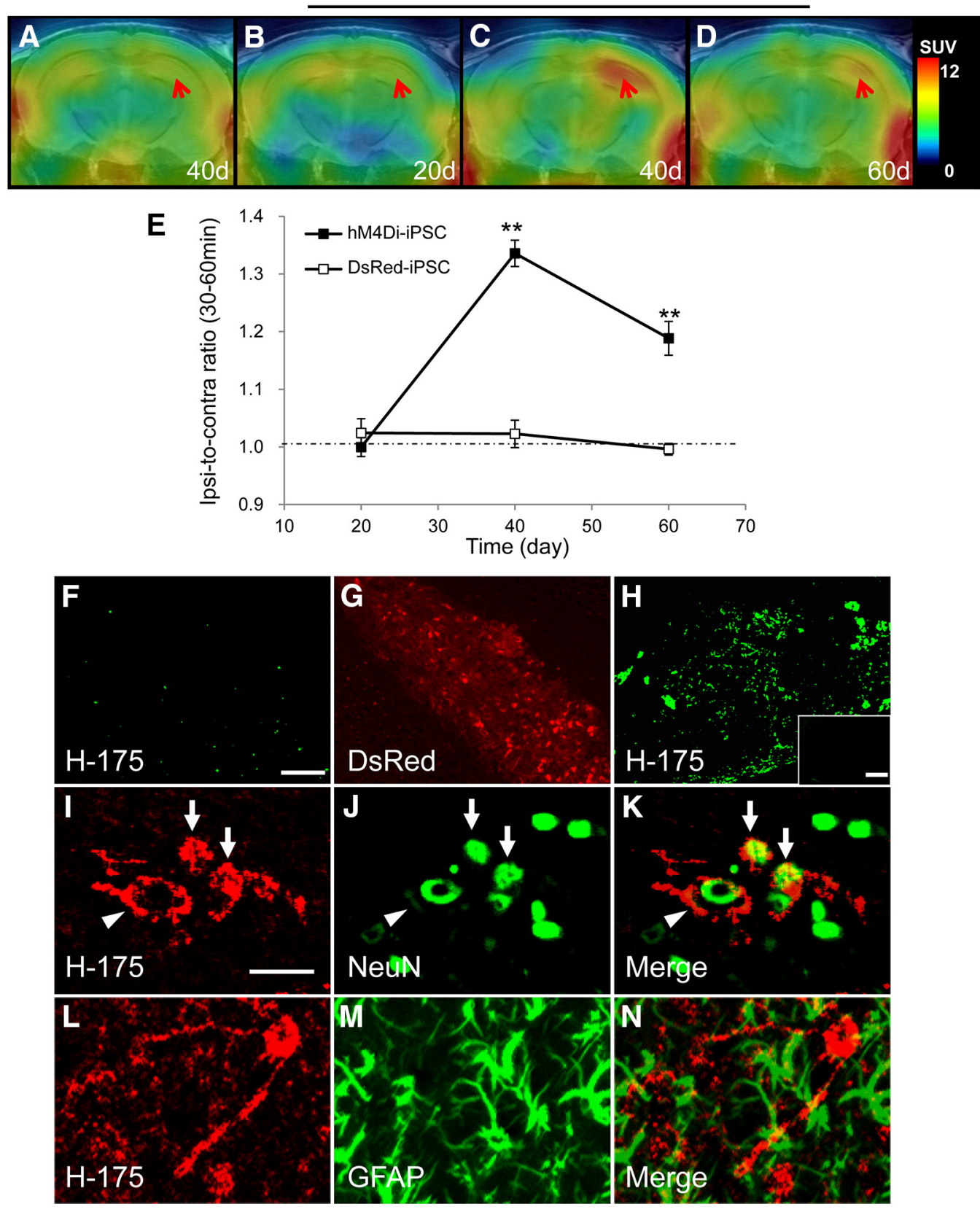

Figure 8. Neuronal differentiation of iPSC-derived cells captured by in vivo PET imaging of hM4Di with $\left[{ }^{11} \mathrm{C}\right] C N O$. $\boldsymbol{A}-\boldsymbol{E}$, Representative $\left[{ }^{11} \mathrm{C}\right] \mathrm{CNO}$-PET images of coronal mouse brain sections containing the neocortex and hippocampus at $20 \mathrm{~d}(\boldsymbol{B}), 40 \mathrm{~d}(\boldsymbol{A}, \boldsymbol{C})$, and $60 \mathrm{~d}(\boldsymbol{D})$ after intrahippocampal implantation of DsRed-iPSC-derived $(\boldsymbol{A})$ or hM4Di-iPSC-derived (B-D) neural cells. PET images were generated as in Figure 2. $\boldsymbol{B}-\boldsymbol{D}$ demonstrate time course images in the same individual mouse. Red arrows indicate the implantation site. Quantification of $\left[{ }^{11} \mathrm{C}\right] C N 0$ retention estimated as a ratio of radioactivity in the implantation site to that in the contralateral corresponding area (ipsi-to-contra ratio) along the course after grafting is shown in $\boldsymbol{E}(n=4-6$ in each graft type). There were significant main effects of genotype of $\operatorname{PSC}\left(F_{(1,24)}=53.07, p<0.01\right.$ by two-way ANOVA $)$ and time $\left(F_{(2,24)}=21.27, p<0.01\right)$ on the ratio. The accumulation of $\left[{ }^{11} \mathrm{C}\right] \mathrm{CN} 0$ in the hippocampus implanted with hM4Di-iPSC-derived cells was significantly increased at 40 and $60 \mathrm{~d}$ after implantation compared with the corresponding region implanted with DsRed-iPSC-derived cells $\left({ }^{* *} p<\right.$ 0.01 by Bonferroni's test for multiple comparisons after ANOVA). $\boldsymbol{F}-\boldsymbol{N}$, hM4Di expression in exogenous iPSC-derived neural cells. The double-channel images illustrating immunostaining of $\mathrm{H}-175$ $(\boldsymbol{F})$ and DsRed fluorescence $(\boldsymbol{G})$ in an individual mouse at $40 \mathrm{~d}$ after implantation of DsRed-PSC-derived cells in the hippocampus exhibited no overt H-175 immunoreactivity in the DsRed-positive grafts. There was noticeable $\mathrm{H}-175$ immunoreactivity in the hippocampus at $40 \mathrm{~d}$ after implantation of hM4Di-iPSC-derived cells $(\boldsymbol{H})$. The insert in $\boldsymbol{H}$ demonstrates the immunoreactivity in the corresponding contralateral region. Double-immunostaining brain sections from the same individual with $\mathrm{H}-175(\boldsymbol{I}, \boldsymbol{L}$, and red in $K$ and $\boldsymbol{N}$ ) and antibody against a marker for mature neurons (NeuN; $\boldsymbol{J}$ and green in $\boldsymbol{K}$ ) or astrocytes (GFAP; $\boldsymbol{M}$ and green in $\boldsymbol{N}$ ) indicated that hM4Di was expressed in neurons, but not in astrocytes. Arrows in $\boldsymbol{I}-\boldsymbol{K}$ indicate relatively small neurons derived from grafts with $\mathrm{H}-175$ immunolabeling in cell surface membrane and $\mathrm{NeuN}(+)$ cytoplasm, which may be less mature. In putatively well matured, large-sized neurons differentiated from grafted progenitors $(\boldsymbol{I}-\boldsymbol{K}$, arrowheads), $\mathrm{H}-175$ immunoreactivity was nearly fully translocated to neuritic processes and cell surface membranes surrounding NeuN $(+)$ cytoplasm. The immunohistochemical images are representative of 5 mice in each implantation group. Error bars represent SE. Scale bars: $\boldsymbol{F}-\boldsymbol{H}, 60 \mu \mathrm{m}$; insert in $\boldsymbol{H}, 200 \mu \mathrm{m} ; \boldsymbol{I}-\boldsymbol{N}, 20 \mu \mathrm{m}$.

between CNO and CLZ documented in a previous human study (Schaber et al., 1998).

The current hM4Di-CNO system has hitherto been the sole practical and noninvasive technique shown to be applicable to specific visualization and functional suppression of endogenous and exogenous nontumor cells in the brain without BBB disruptions. Likewise, the combined use of hM3Dq and $\mathrm{CNO}$ would permit intracranial implantation of visible and operable grafts. A previous report docu- 
mented the application of a PET tracer to the demonstration of the long-term survival of therapeutic mesenchymal stem cells implanted in a porcine myocardial infarction model (Perin et al., 2011). However, that study used a substrate-specific mutant derivative of herpes virus type 1 thymidine kinase as a reporter and its specific radioligand, a radiolabeled nucleoside ana$\log$, is not applicable to monitoring of implanted cells in CNS tissues because of its inefficient penetration through the BBB. Recent studies have documented the development of mutated cannabinoid receptor type 2 (CB2) and its specific radioligand as a PET-applicable reporter system targeting the brain (Vandeputte et al., 2011). The mutant $\mathrm{CB} 2$ receptor exerts little reactivity with endogenous cannabinoids, but does not act as DREADD because there exists no agonistic ligand with selectivity for mutant versus native CB2 receptors (Palazuelos et al., 2009; Stella, 2010). In addition to hM3Dq and hM4Di DREADDs, families of engineered GPCRs referred to as receptors activated solely by synthetic ligands (RASSLs) can be activated by brain-entering small molecules (Conklin et al., 2008). However, ligands for these first-generation RASSLs either did not display high affinity or they cross-reacted with endogenous receptors. The future creation of a new DREADD class in conjunction with hM3Dq and hM4Di would facilitate differential imaging and control of multiple neuronal and glial populations contained in the implant with the aid of appropriate cell-type-specific promoters.

The use of DREADD is also complementary to optogenetic approaches for the manipulation of neuronal and glial excitability in living brains (Nagel et al., 2002; Nagel et al., 2003). Channelrhodopsins offer temporal accuracy at a millisecond scale in operating the depolarization of target cells, whereas less invasive long-term modulation of cellular activity is enabled by chemogenetics, as exemplified by DREADDs. Mechanisms underlying light-induced activation of neurons and glia are yet to be clarified, although the transmembrane transport of protons has been implicated (Feldbauer et al., 2009). This might differ from intracellular signaling pathways downstream of hM3Dq and hM4Di stimulations, which are virtually identical to native GPCR signaling. Channelrhodopsins would be expressed in iPSC-derived neurons and glia, but the applicability to PET imaging renders DREADD more translatable to humans as a visible component.

Utilization of hM4Di-iPSCs is suitable for replacement therapies compensating for massive neuronal loss in neurodegenerative disorders and might accordingly be more beneficial than bar, $100 \mu \mathrm{m}(\boldsymbol{F}, \boldsymbol{G})$.
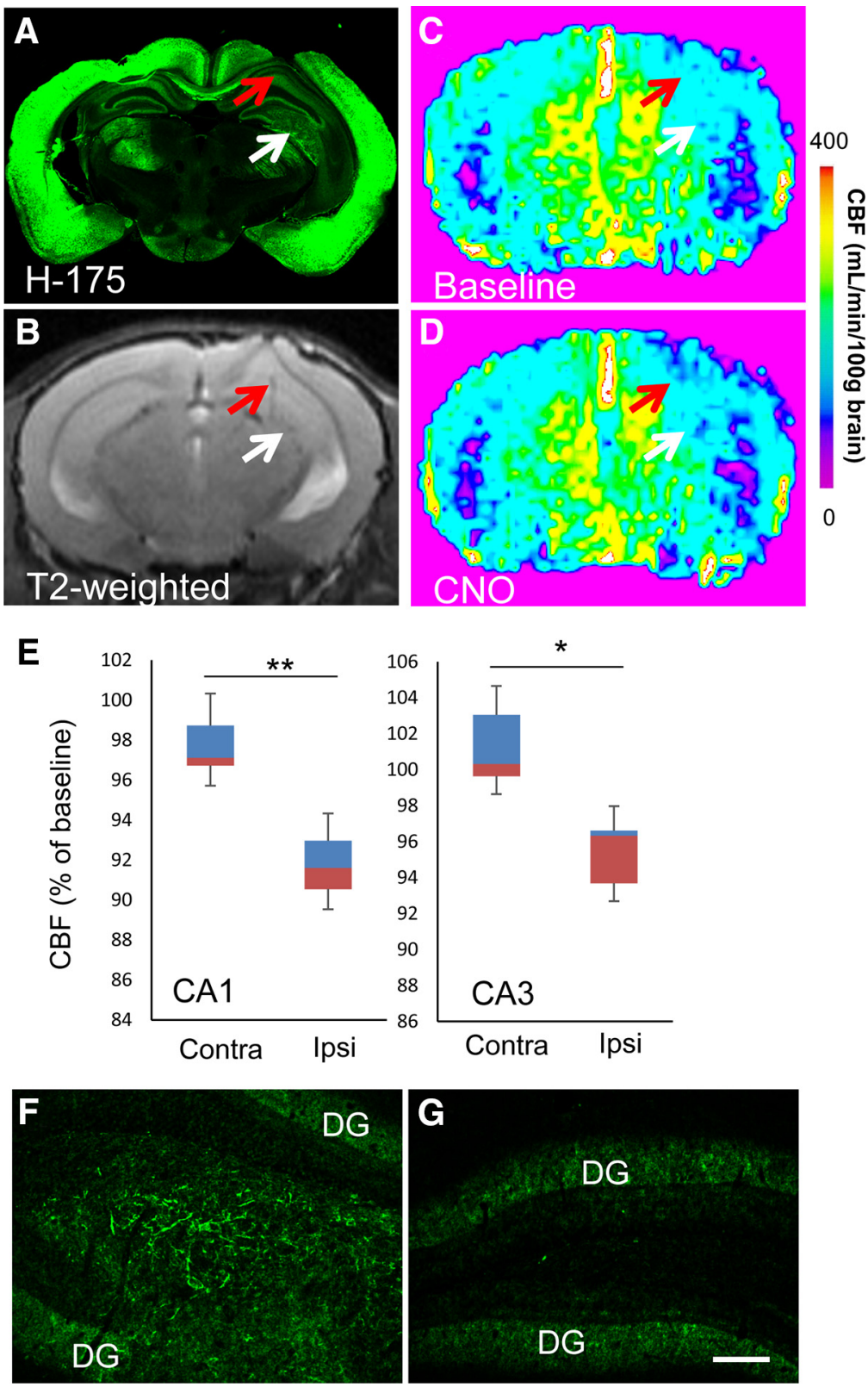

Figure 9. In vivo imaging assessments of the functionality of hM4Di-iPSC-derived neuronal grafts. $A-D$, Representative postmortem microscopic $(\boldsymbol{A})$ and antemortem T2-weighted $(\boldsymbol{B})$ and ASL $(\boldsymbol{C}, \boldsymbol{D})$ MRI images of an adult mouse brain at $40 \mathrm{~d}$ after implantation of hM4Di-iPSC-derived grafts. A low-power photomicrograph illustrates immunolabeling of endogenous and graftderived M4 mAChRs with H-175 (A). Red and white arrows indicate the ipsilateral hippocampal CA1 sector and hilus, respectively. This mouse underwent repeated ASL-MRI at 40, 46, and $52 \mathrm{~d}$ after implantation. Scale bar indicates CBF measures in $\boldsymbol{C}$ and $\boldsymbol{D}$. $\boldsymbol{E}$, Quantitative assays of CNO-induced CBF changes in hippocampal CA1 and CA3 sectors. Data are displayed in boxplots. The bottom and top of rectangles indicate the first and third quartiles, respectively. A horizontal line inside the rectangles shows the median and the "whiskers" above and below the rectangles express the maximum and minimum values, respectively. Quantitative analysis of these three assays demonstrated that (BF was decreased significantly in the implantation site (hilus/CA3), as well as the ipsilateral CA1 sector, in response to CNO $\left(n=3, t=15.808\right.$ and $t=4.635$ for CA1 and hilus/CA3, respectively, ${ }^{*} p<0.05,{ }^{*} p<$ 0.01 , by paired $t$ test, versus the corresponding contralateral regions). The brain of this mouse was collected after the last MRI scan for postmortem analysis. $\boldsymbol{F}, \mathbf{G}, \mathrm{H}-175$ immunoreactivity in the hippocampal hilus $(\boldsymbol{F})$ implanted with hM4Di-iPSC-derived cells, in sharp contrast with the absence of detectable signals in the contralateral hilar region $(\boldsymbol{G})$. Immunofluorescence signals in the dentate gyrus (DG) were primarily derived from expression of endogenous M4 mAChR. Ipsi, Ipsilateral; Contra, contralateral. Scale

replacement by viral-vector-mediated gene transfer to surviving cells in these conditions. As demonstrated here, DREADD-PET provides the means to monitoring neuronal and glial differentiation of progenitors. Moreover, operations of therapeutic cells with DREADDs are also beneficial for cell replacement therapies, 
as exemplified in a recent work demonstrating an increased dopamine release and sequential therapeutic effects by exclusive stimulation of hM3Dq-expressing grafts by $\mathrm{CNO}$ in an animal model of Parkinson's disease (Dell'Anno et al., 2014). Metabotropic DREADD is also likely to regulate the differentiation and survival of grafted neural progenitors via cAMP response element-binding protein and extracellular regulated kinase and related pathways dependent on cAMP or phospholipase C (Giachino et al., 2005; Greenwood and Dragunow, 2010; Zhong et al., 2014). Along the course of replacement treatments, the synaptic connectivity between graft and host neurons could be examined with the DREADD-CNO system. Our observations imply that the growth of axons from grafts might be guided by existing nerve fiber pathways such as the subcortical white matter tract and the Schaffer collateral path, analogous to axonal fasciculation during development and axonal regeneration (Horner and Gage, 2000). This would provide strategies for the rewiring of injured neural networks using cellular implants. Interestingly, acetylcholine acts as an axonal guidance cue and muscarinic receptors are enriched in growth cone membranes of developing neurons, eliciting an intracellular calcium response (Resende et al., 2008) or alterations of cAMP or phospholipase C signaling and consequent phosphorylation/dephosphorylation of cytoskeletal constituents (Song et al., 1997). Therefore, stimulation of hM3Dq and hM4Di by CNO would serve as a manipulator of axonal growth in a planned time range. In addition, DREADDs flanked by loxP could be expressed selectively in an individual circuit by injection of a retrogradely transportable gene-transfer vector (Kinoshita et al., 2012) carrying Cre recombinase into a projection site.

Transformation of grafts to teratomas and other neoplasms may occur after implantation and could be detected by PET imaging of cerebral glucose utilization. Our data suggested that PET with $\left[{ }^{18} \mathrm{~F}\right]$ fluoro-deoxy-glucose is capable of visualizing the generation of teratomas from a small but significant subset of implants (data not shown). This problem might be solved by the development of new technologies such as neuron-directed programming of stem cells and neuronal reprogramming of astrocytes and fibroblasts (Hester et al., 2011; Liu et al., 2013; Dell'Anno et al., 2014). In addition, it has also been documented that $\mathrm{mAChRs}$ are involved mechanistically in the proliferation of tumors (Shah et al., 2009) and interaction between CNO and hM3Dq or hM4Di may contribute to selective suppression of tumorigenesis.

The aforementioned multiple regulatory effects of hM3Dq and hM4Di stimulations on grafts indicate the need for fine tuning of CNO-provoked postreceptor signaling in a timely fashion and this would be aided technically by assessing the in vivo occupancy of these receptors by CNO. Quantification of receptor occupancy could be performed by PET measurement of $\left[{ }^{11} \mathrm{C}\right] \mathrm{CNO}$ binding competitively blocked by pharmacoactive, unlabeled CNO.

To summarize, the current work has offered new multimodal PET and MRI approaches to chemogenetics with a functional and therapeutic reporter probe. It is of particular significance that incorporation of DREADDs in neuronal implants offers descriptive and functional tests of the graft and functional restoration of interneuronal connectivity modifiable by an exogenous drug-like compound. This technology is accordingly capable of fortifying the utility of iPSCs in cell replacement therapies for neurodegenerative disorders (Wernig et al., 2008; Hargus et al., 2010; Tsuji et al.,
2010) by granting in vivo visibility and operability to these grafts.

\section{References}

Abematsu M, Tsujimura K, Yamano M, Saito M, Kohno K, Kohyama J, Namihira M, Komiya S, Nakashima K (2010) Neurons derived from transplanted neural stem cells restore disrupted neuronal circuitry in a mouse model of spinal cord injury. J Clin Invest 120:3255-3266. CrossRef Medline

Alexander GM, Rogan SC, Abbas AI, Armbruster BN, Pei Y, Allen JA, Nonneman RJ, Hartmann J, Moy SS, Nicolelis MA, McNamara JO, Roth BL (2009) Remote control of neuronal activity in transgenic mice expressing evolved G protein-coupled receptors. Neuron 63:27-39. CrossRef Medline

Armbruster BN, Li X, Pausch MH, Herlitze S, Roth BL (2007) Evolving the lock to fit the key to create a family of $\mathrm{G}$ protein-coupled receptors potently activated by an inert ligand. Proc Natl Acad Sci U S A 104:51635168. CrossRef Medline

Bender D, Holschbach M, Stöcklin G (1994) Synthesis of n.c.a. carbon-11 labelled clozapine and its major metabolite clozapine- $N$-oxide and comparison of their biodistribution in mice. Nucl Med Biol 21:921-925. CrossRef Medline

Conklin BR, Hsiao EC, Claeysen S, Dumuis A, Srinivasan S, Forsayeth JR, Guettier JM, Chang WC, Pei Y, McCarthy KD, Nissenson RA, Wess J, Bockaert J, Roth BL (2008) Engineering GPCR signaling pathways with RASSLs. Nat Methods 5:673-678. CrossRef Medline

Dell'Anno MT, Caiazzo M, Leo D, Dvoretskova E, Medrihan L, Colasante G, Giannelli S, Theka I, Russo G, Mus L, Pezzoli G, Gainetdinov RR, Benfenati F, Taverna S, Dityatev A, Broccoli V (2014) Remote control of induced dopaminergic neurons in parkinsonian rats. J Clin Invest 124: 3215-3229. CrossRef Medline

Doi D, Morizane A, Kikuchi T, Onoe H, Hayashi T, Kawasaki T, Motono M, Sasai Y, Saiki H, Gomi M, Yoshikawa T, Hayashi H, Shinoyama M, Refaat MM, Suemori H, Miyamoto S, Takahashi J (2012) Prolonged maturation culture favors a reduction in the tumorigenicity and the dopaminergic function of human ESC-derived neural cells in a primate model of Parkinson's disease. Stem Cells 30:935-945. CrossRef Medline

Duffy BA, Weitz AJ, Lee JH (2014) In vivo imaging of transplanted stem cells in the central nervous system. Curr Opin Genet Dev 28:83-88. CrossRef Medline

Feldbauer K, Zimmermann D, Pintschovius V, Spitz J, Bamann C, Bamberg E (2009) Channelrhodopsin-2 is a leaky proton pump. Proc Natl Acad Sci U S A 106:12317-12322. CrossRef Medline

Fujimoto Y, Abematsu M, Falk A, Tsujimura K, Sanosaka T, Juliandi B, Semi K, Namihira M, Komiya S, Smith A, Nakashima K (2012) Treatment of a mouse model of spinal cord injury by transplantation of human induced pluripotent stem cell-derived long-term self-renewing neuroepitheliallike stem cells. Stem Cells 30:1163-1173. CrossRef Medline

Giachino C, De Marchis S, Giampietro C, Parlato R, Perroteau I, Schütz G, Fasolo A, Peretto P (2005) cAMP response element-binding protein regulates differentiation and survival of newborn neurons in the olfactory bulb. J Neurosci 25:10105-10118. CrossRef Medline

Greenwood JM, Dragunow M (2010) M3 muscarinic receptors promote cell survival through activation of the extracellular regulated kinase (ERK1/2) pathway. Eur J Pharmacol 640:38-45. CrossRef Medline

Guettier JM, Gautam D, Scarselli M, Ruiz de Azua I, Li JH, Rosemond E, Ma X, Gonzalez FJ, Armbruster BN, Lu H, Roth BL, Wess J (2009) A chemical-genetic approach to study $G$ protein regulation of beta cell function in vivo. Proc Natl Acad Sci U S A 106:19197-19202. CrossRef Medline

Hargus G, Cooper O, Deleidi M, Levy A, Lee K, Marlow E, Yow A, Soldner F, Hockemeyer D, Hallett PJ, Osborn T, Jaenisch R, Isacson O (2010) Differentiated Parkinson patient-derived induced pluripotent stem cells grow in the adult rodent brain and reduce motor asymmetry in Parkinsonian rats. Proc Natl Acad Sci U S A 107:15921-15926. CrossRef Medline

Herschman HR (2003) Micro-PET imaging and small animal models of disease. Curr Opin Immunol 15:378-384. CrossRef Medline

Hester ME, Murtha MJ, Song S, Rao M, Miranda CJ, Meyer K, Tian J, Boulting G, Schaffer DV, Zhu MX, Pfaff SL, Gage FH, Kaspar BK (2011) Rapid and efficient generation of functional motor neurons from human pluripotent stem cells using gene delivered transcription factor codes. Mol Ther 19:1905-1912. CrossRef Medline 
Horner PJ, Gage FH (2000) Regenerating the damaged central nervous system. Nature 407:963-970. CrossRef Medline

Ji B, Maeda J, Sawada M, Ono M, Okauchi T, Inaji M, Zhang MR, Suzuki K, Ando K, Staufenbiel M, Trojanowski JQ, Lee VM, Higuchi M, Suhara T (2008) Imaging of peripheral benzodiazepine receptor expression as biomarkers of detrimental versus beneficial glial responses in mouse models of Alzheimer's and other CNS pathologies. J Neurosci 28:12255-12267. CrossRef Medline

Kim SG (1995) Quantification of relative cerebral blood flow change by flow-sensitive alternating inversion recovery (FAIR) technique: application to functional mapping. Magn Reson Med 34:293-301. CrossRef Medline

Kinoshita M, Matsui R, Kato S, Hasegawa T, Kasahara H, Isa K, Watakabe A, Yamamori T, Nishimura Y, Alstermark B, Watanabe D, Kobayashi K, Isa $\mathrm{T}$ (2012) Genetic dissection of the circuit for hand dexterity in primates. Nature 487:235-238. CrossRef Medline

Kumagai G, Okada Y, Yamane J, Nagoshi N, Kitamura K, Mukaino M, Tsuji O, Fujiyoshi K, Katoh H, Okada S, Shibata S, Matsuzaki Y, Toh S, Toyama Y, Nakamura M, Okano H (2009) Roles of ES cell-derived gliogenic neural stem/progenitor cells in functional recovery after spinal cord injury. PLoS One 4:e7706. CrossRef Medline

Kvon EZ (2015) Using transgenic reporter assays to functionally characterize enhancers in animals. Genomics 106:185-192. CrossRef Medline

Lammertsma AA, Bench CJ, Hume SP, Osman S, Gunn K, Brooks DJ, Frackowiak RS (1996) Comparison of methods for analysis of clinical $\left[{ }^{11} \mathrm{C}\right]$ raclopride studies. J Cereb Blood Flow Metab 16:42-52. Medline

Lin G, McKay G, Midha KK (1996) Characterization of metabolites of clozapine $\mathrm{N}$-oxide in the rat by micro-column high performance liquid chromatography/mass spectrometry with electrospray interface. J Pharm Biomed Anal 14:1561-1577. CrossRef Medline

Liu ML, Zang T, Zou Y, Chang JC, Gibson JR, Huber KM, Zhang CL (2013) Small molecules enable neurogenin 2 to efficiently convert human fibroblasts into cholinergic neurons. Nat Commun 4:2183. CrossRef Medline

Maeda J, Ji B, Irie T, Tomiyama T, Maruyama M, Okauchi T, Staufenbiel M, Iwata N, Ono M, Saido TC, Suzuki K, Mori H, Higuchi M, Suhara T (2007) Longitudinal, quantitative assessment of amyloid, neuroinflammation, and anti-amyloid treatment in a living mouse model of Alzheimer's disease enabled by positron emission tomography. J Neurosci 27: 10957-10968. CrossRef Medline

Maekawa M, Yamaguchi K, Nakamura T, Shibukawa R, Kodanaka I, Ichisaka T, Kawamura Y, Mochizuki H, Goshima N, Yamanaka S (2011) Direct reprogramming of somatic cells is promoted by maternal transcription factor Glis1. Nature 474:225-229. CrossRef Medline

Nagai Y, Kikuchi E, Lerchner W, Inoue KI, Oh-Nishi A, Kaneko H, Kato Y, Hori Y, Ji B, Kumata K, Zang M-R, Aoki I, Suhara T, Takada M, Higuchi M, Richmond BJ, Minamimoto T (2014) In vivo PET imaging of the behaviorally active designer receptor in macaque monkeys. Program No 462.22. 2014 Neuroscience Meeting Planner. Washington, DC: Society for Neuroscience, 2014. Online.

Nagel G, Ollig D, Fuhrmann M, Kateriya S, Musti AM, Bamberg E, Hegemann P (2002) Channelrhodopsin-1: a light-gated proton channel in green algae. Science 296:2395-2398. CrossRef Medline

Nagel G, Szellas T, Huhn W, Kateriya S, Adeishvili N, Berthold P, Ollig D, Hegemann P, Bamberg E (2003) Channelrhodopsin-2, a directly lightgated cation-selective membrane channel. Proc Natl Acad Sci U S A 100: 13940-13945. CrossRef Medline

Nakagawa M, Koyanagi M, Tanabe K, Takahashi K, Ichisaka T, Aoi T, Okita K, Mochiduki Y, Takizawa N, Yamanaka S (2008) Generation of induced pluripotent stem cells without Myc from mouse and human fibroblasts. Nat Biotechnol 26:101-106. Medline

Nawaratne V, Leach K, Suratman N, Loiacono RE, Felder CC, Armbruster BN, Roth BL, Sexton PM, Christopoulos A (2008) New insights into the function of M4 muscarinic acetylcholine receptors gained using a novel allosteric modulator and a DREADD (designer receptor exclusively activated by a designer drug). Mol Pharmacol 74:1119-1131. CrossRef Medline

Okada S, Ishii K, Yamane J, Iwanami A, Ikegami T, Katoh H, Iwamoto Y, Nakamura M, Miyoshi H, Okano HJ, Contag CH, Toyama Y, Okano H (2005) In vivo imaging of engrafted neural stem cells: its application in evaluating the optimal timing of transplantation for spinal cord injury. FASEB J 19:1839-1841. Medline
Palazuelos J, Aguado T, Pazos MR, Julien B, Carrasco C, Resel E, Sagredo O, Benito C, Romero J, Azcoitia I, Fernández-Ruiz J, Guzmán M, GalveRoperh I (2009) Microglial CB2 cannabinoid receptors are neuroprotective in Huntington's disease excitotoxicity. Brain 132:3152-3164. CrossRef Medline

Perin EC, et al. (2011) Imaging long-term fate of intramyocardially implanted mesenchymal stem cells in a porcine myocardial infarction model. PLoS One 6:e22949. CrossRef Medline

Qian S, Jiang P, Guan XM, Singh G, Trumbauer ME, Yu H, Chen HY, Van de Ploeg LH, Zheng H (1998) Mutant human presenilin 1 protects presenilin 1 null mouse against embryonic lethality and elevates Abeta1-42/43 expression. Neuron 20:611-617. CrossRef Medline

Raoult H, Petr J, Bannier E, Stamm A, Gauvrit JY, Barillot C, Ferré JC (2011) Arterial spin labeling for motor activation mapping at $3 \mathrm{~T}$ with a $32-$ channel coil: reproducibility and spatial accuracy in comparison with BOLD fMRI. Neuroimage 58:157-167. CrossRef Medline

Resende RR, Gomes KN, Adhikari A, Britto LR, Ulrich H (2008) Mechanism of acetylcholine-induced calcium signaling during neuronal differentiation of P19 embryonal carcinoma cells in vitro. Cell Calcium 43: 107-121. CrossRef Medline

Sanchez-Pernaute R, Lee H, Patterson M, Reske-Nielsen C, Yoshizaki T, Sonntag KC, Studer L, Isacson O (2008) Parthenogenetic dopamine neurons from primate embryonic stem cells restore function in experimental Parkinson's disease. Brain 131:2127-2139. CrossRef Medline

Schaber G, Stevens I, Gaertner HJ, Dietz K, Breyer-Pfaff U (1998) Pharmacokinetics of clozapine and its metabolites in psychiatric patients: plasma protein binding and renal clearance. Br J Clin Pharmacol 46:453-459. Medline

Schenborn E, Groskreutz D (1999) Reporter gene vectors and assays. Mol Biotechnol 13:29-44. CrossRef Medline

Shah N, Khurana S, Cheng K, Raufman JP (2009) Muscarinic receptors and ligands in cancer. Am J Physiol Cell Physiol 296:C221-C232. CrossRef Medline

Smith AJ, Blumenfeld H, Behar KL, Rothman DL, Shulman RG, Hyder F (2002) Cerebral energetics and spiking frequency: the neurophysiological basis of fMRI. Proc Natl Acad Sci U S A 99:10765-10770. CrossRef Medline

Song HJ, Ming GL, Poo MM (1997) cAMP-induced switching in turning direction of nerve growth cones. Nature 388:275-279. CrossRef Medline

Stella N (2010) Cannabinoid and cannabinoid-like receptors in microglia, astrocytes, and astrocytomas. Glia 58:1017-1030. CrossRef Medline

Thakur B, Chatterjee S, Chaudhury S, Ray P (2015) Molecular imaging of therapeutic potential of reporter probes. Curr Drug Targets 16:645-657. CrossRef Medline

Tsuji O, et al. (2010) Therapeutic potential of appropriately evaluated safeinduced pluripotent stem cells for spinal cord injury. Proc Natl Acad Sci U S A 107:12704-12709. CrossRef Medline

Vande Velde G, Raman Rangarajan J, Vreys R, Guglielmetti C, Dresselaers T, Verhoye M, Van der Linden A, Debyser Z, Baekelandt V, Maes F, Himmelreich U (2012) Quantitative evaluation of MRI-based tracking of ferritin-labeled endogenous neural stem cell progeny in rodent brain. Neuroimage 62:367-380. CrossRef Medline

Vandeputte C, Evens N, Toelen J, Deroose CM, Bosier B, Ibrahimi A, Van der Perren A, Gijsbers R, Janssen P, Lambert DM, Verbruggen A, Debyser Z, Bormans G, Baekelandt V, Van Laere K (2011) A PET brain reporter gene system based on type 2 cannabinoid receptors. J Nucl Med 52:11021109. CrossRef Medline

Vintersten K, Monetti C, Gertsenstein M, Zhang P, Laszlo L, Biechele S, Nagy A (2004) Mouse in red: red fluorescent protein expression in mouse ES cells, embryos, and adult animals. Genesis 40:241-246. CrossRef Medline

Wernig M, Zhao JP, Pruszak J, Hedlund E, Fu D, Soldner F, Broccoli V, Constantine-Paton M, Isacson O, Jaenisch R (2008) Neurons derived from reprogrammed fibroblasts functionally integrate into the fetal brain and improve symptoms of rats with Parkinson's disease. Proc Natl Acad Sci U S A 105:5856-5861. CrossRef Medline

Zhong P, Liu X, Zhang Z, Hu Y, Liu SJ, Lezama-Ruiz M, Joksimovic M, Liu QS (2014) Cyclin-dependent kinase 5 in the ventral tegmental area regulates depression-related behaviors. J Neurosci 34:6352-6366. CrossRef Medline 